\title{
Mechanisms and capacity of high-pressure soaking after hydraulic fracturing in tight/shale oil reservoirs
}

\author{
Jing Wang ${ }^{1,2} \cdot$ Hui-Qing Liu ${ }^{1} \cdot$ Gen-Bao Qian ${ }^{3} \cdot$ Yong-Can Peng ${ }^{3}$
}

Received: 29 July 2020 / Accepted: 14 September 2020 / Published online: 9 November 2020

(c) The Author(s) 2020

\begin{abstract}
Huff-n-puff by water has been conducted to enhance oil recovery after hydraulic fracturing in tight/shale oil reservoirs. However, the mechanisms and capacity are still unclear, which significantly limits the application of this technique. In order to figure out the mechanisms, the whole process of pressurizing, high-pressure soaking, and depressurizing was firstly discussed, and a mechanistic model was established. Subsequently, the simulation model was verified and employed to investigate the significances of high-pressure soaking, the contributions of different mechanisms, and the sensitivity analysis in different scenarios. The results show that high-pressure soaking plays an essential role in oil production by both imbibition and elasticity after hydraulic fracturing. The contribution of imbibition increases as the increase in bottom hole pressure (BHP), interfacial tension, and specific surface area, but slightly decreases as the oil viscosity increases. In addition, it first decreases and then slightly increases with the increase in matrix permeability. The optimal soaking time is linear with the increases of both oil viscosity and BHP and logarithmically declines with the increase in matrix permeability and specific surface area. Moreover, it shows a rising tendency as the interficial tension (IFT) increases. Overall, a general model was achieved to calculate the optimal soaking time.
\end{abstract}

Keywords Enhanced oil recovery $\cdot$ High-pressure soaking $\cdot$ Huff-n-puff $\cdot$ Imbibition $\cdot$ Tight/shale oil

\section{Introduction}

Tight/shale oil resource extensively distributes around the world. It is regarded as a promising resource to provide fossil energy in the future. Therefore, how to efficiently exploit these resources comes into our focus. However, the permeability is on the order of $10^{-3}$ to $10^{-1}$ millidarcy in this kind of reservoir. Industrial capacity cannot be yielded even using conventional horizontal wells. Extensive field experience shows that hydraulic fracturing can effectively improve

Edited by Yan-Hua Sun

Jing Wang

wangjing8510@163.com

1 State Key Laboratory of Petroleum Resources and Prospecting, China University of Petroleum (Beijing), Beijing 102249, China

2 Shaanxi Cooperative Innovation Center of Unconventional Oil and Gas Exploration and Development, Xi' an Shiyou University, Xi' an 710065, Shaanxi, China

3 CNPC Xinjiang Oilfield, Karamay 834000, Xinjiang, China the development effect of unconventional resources (Holditch and Tschirhart 2005; Liang et al. 2017). Nevertheless, the oil recovery is still lower than $10 \%$ by depletion-drive after hydraulic fracturing (Manrique et al. 2010; Kathel and Mohanty 2013; Teklu et al. 2016). Therefore, numerous attempts have been made to enhance oil recovery. In some oilfields, water flooding has been conducted. However, if the well spacing is larger, the producers are not responding under a very high injection pressure (Song and Yang 2013; Kong et al. 2016; Mansour et al. 2017). Conversely, if the well spacing is smaller, water channels faster to the producers through the hydraulic fractures (Thomas et al. 2014; Li et al. 2015; Pourabdollah 2018). Consequently, huff-n-puff by fracturing fluids or produced water has been tested in several tight oil pilots, and positive effects have been achieved (Li et al. 2015; Li 2015; Tuero et al. 2017).

Generally, the oil production mechanism of water soaking is attributed to imbibition (Wang et al. 2018). Imbibition is significantly important in tight oil reservoir since capillary force is more dominant in such Formation (Yang et al. 2018). Most studies suggest that oil can be driven out by imbibition even in mixed-wet samples (Cai et al. 2014; Dutta et al. 
2012; Habibi et al. 2015). Dutta et al. (2012) reported that although the permeability of tight rock is very low, the small characteristic radius suppresses a stronger effect of capillarity; the impacts of permeability and porosity on imbibition should be taken into account. Habibi et al. (2015) proposed that pore surface usually contains both oil-wet and waterwet minerals in tight rock, so the remaining oil might be trapped in small oil-wet pores. Wang et al. (2012) found that surfactant can alter the oil-wet or mixed-wet cores toward water-wet to displace out more oil than brine.

Spontaneous imbibition plays a significant role in water uptake into porous media during long shut-in which could last for a few days in some cases. After a long time, when the water-phase pressure that pushes the water into the formation has already dissipated, capillary forces dominate (Rangel-German and Kovscek 2002). However, forced imbibition is different from spontaneous imbibition, whose driving force is capillary force alone. Forced imbibition is achieved by injecting fluid into a sample at a constant pressure higher than that of the sample displacement pressure (Roychaudhuri et al. 2014). The wetting phase firstly enters the capillary for a certain length to enhance the elastic energy. After pressure equilibrium, spontaneous imbibition happens to expel the oil. Roychaudhuri et al. (2014) conducted forced imbibition to study the efficacy of surfactant under high-pressure scenarios and found that both spontaneous and forced imbibition experiments should be applied to evaluate the effect of surfactant on liquid dynamics in tight shales. Actually, the water-phase pressure in macro-fractures is much higher than that in matrix after hydraulic fracturing; the pressure propagates during soaking. Moreover, higher pressure is favorable to recover the conductivity of both macro-fractures and natural fractures by water stimulation. Therefore, when production restarts after soaking, elastic energy of both rock and fluid will contribute to oil production as that in fractured reservoirs (Finkbeiner et al. 2010; Omosebi and Igbokoyi 2012; Valiveti et al. 2015), which increases the complexity of oil production mechanisms.

For the reasons outlined above, there are several issues to be clarified for the strategy as follows: (1) what is/are the driving force(s) to expel oil out from matrix? (2) If the oil is produced by the mechanisms of elastic energy and imbibition, how much does each one contribute? (3) How long should the cycle soaking take? and (4) what are the production performances of huff-n-puff? The answers are the keys to optimizing soaking strategy and improving the development effect. In order to figure out the answers, the whole process of pressurizing, high-pressure soaking, and depressurizing was firstly discussed, and a mechanistic model including the essential mechanisms was established and verified. The confusing problems above are resolved by the model with an excellent matching result. This work could help us understand the mechanisms and capacity of oil production by high-pressure soaking more clearly and better design EOR strategy in tight/shale oil reservoirs.

\section{Forced imbibition during high-pressure soaking}

Spontaneous imbibition is usually classified as co-current and counter-current. The driving force of co-current imbibition is capillary force and gravity (or called buoyancy), yet that of counter-current imbibition is capillary force. However, imbibition under high-pressure scenario is different. Since the inverse Bond number $N_{\mathrm{B}}{ }^{-1}$ is very large in tight oil reservoirs, the impact of gravity can be neglected. The process can be manifested by the sketch maps of forced co-current and counter-current imbibition in a variable capillary, as shown in Figs. 1 and 2, respectively. Figure 1a shows the initial state before fracturing. When fracturing fluid or water is injected, the pressure increases and water enters the capillary from both ends, which is called high-pressure transmission, as shown in Fig. 1b. After high-pressure transmission, the equilibrium water-phase pressure is $P_{\mathrm{rh}}$; thus, the oil-phase pressure is $P_{\mathrm{rh}}+P_{\mathrm{c} 1}$ at the narrow end, and that is $P_{\mathrm{rh}}+P_{\mathrm{c} 2}$ at the wide end. Because the radius of narrow end is smaller, $P_{\mathrm{c} 1}$ is larger than $P_{\mathrm{c} 2}$. Consequently, water enters the capillary from the narrow end, while oil and antecedent water flow out from the wide end, which is the well-known mechanism of co-current imbibition, as shown in Fig. 1c. After soaking for a while, the well opens with a lower bottom hole pressure (BHP). The pressure difference gradually increases between the internal and external fluids as the pressure decreases in fractures. In addition, as the fluid expands and pores shrink, a large amount of fluid is driven out of the capillary, which is called elastic energy release as shown in Fig. 1d. There might be questions why the water proportion increases. The reason is that the permeability at the wide end is larger than that of the narrow end, so oil flows faster from the wide end than water from the narrow end. As a result, more oil gets expelled, and the water saturation increases in the capillary. According to the above analysis, the oil expelled due to pressure decrease is regarded as the contribution of elasticity. The process and mechanisms are similar for counter-current imbibition as in Fig. 2. We can see that it is more favorable for water entering and driving oil out from matrix.

\section{Simulation of forced imbibition with high-pressure soaking}

In order to understand the process and mechanisms of oil production by high-pressure soaking in tight formations more clearly, a simulation method is developed. As can be 


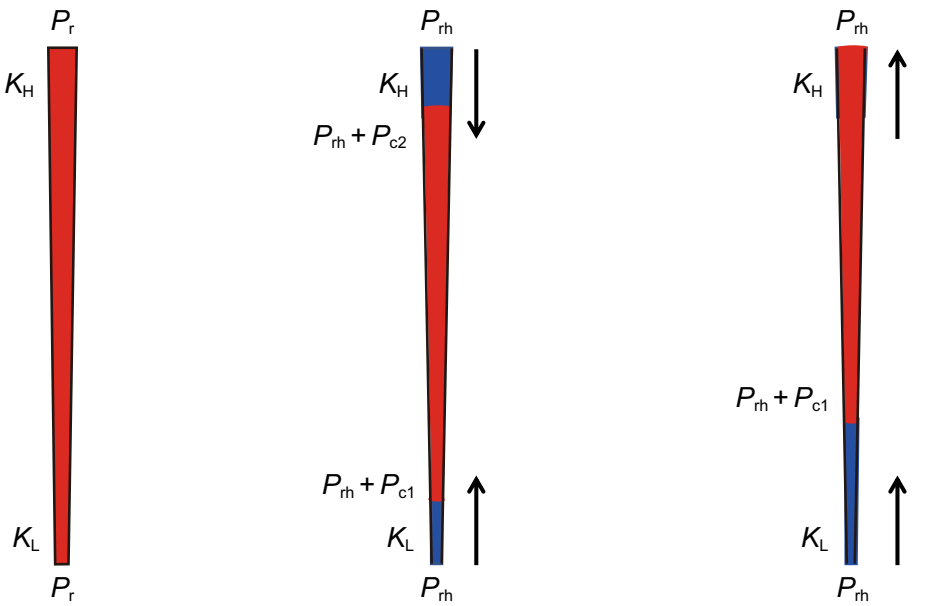

(a) Initial state (b) High pressure transmission (c) Forced imbibition

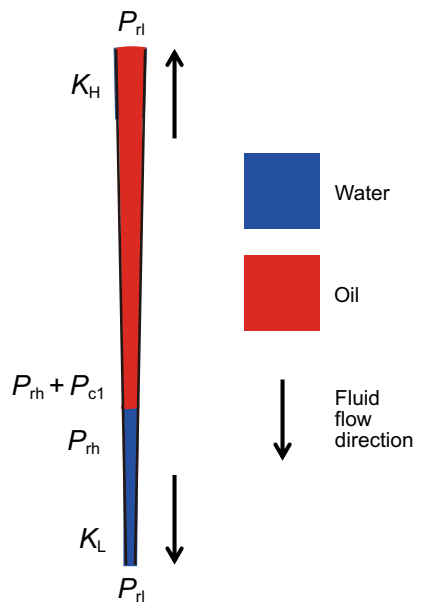

(d) Elastic energy release

Fig. 1 Sketch map of pressurizing-soaking-depressurizing process for co-current imbibition scenario $\left(K_{\mathrm{H}}\right.$, high permeability; $K_{\mathrm{L}}$, low permeability; $P_{\mathrm{r}}$, reservoir pressure; $P_{\mathrm{rl}}$, low reservoir pressure; $P_{\mathrm{rh}}$, high reservoir pressure; $P_{\mathrm{c} 1}$, capillary pressure at the narrow end; $P_{\mathrm{c} 2}$, capillary pressure at the wide end)

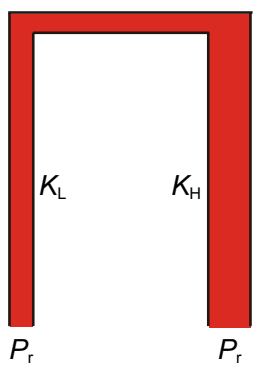

(a) Initial state

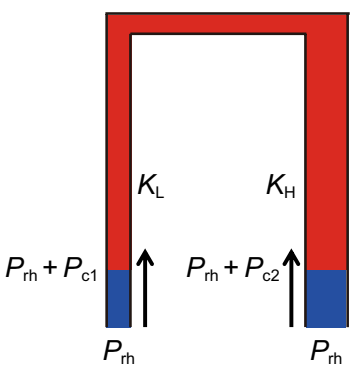

(b) High pressure transmission

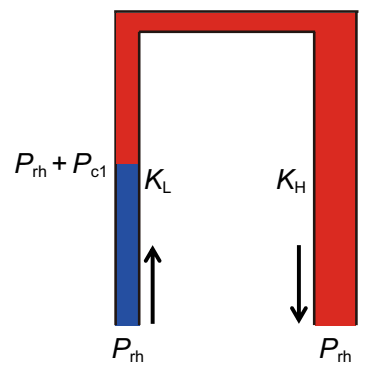

(c) Forced imbibition

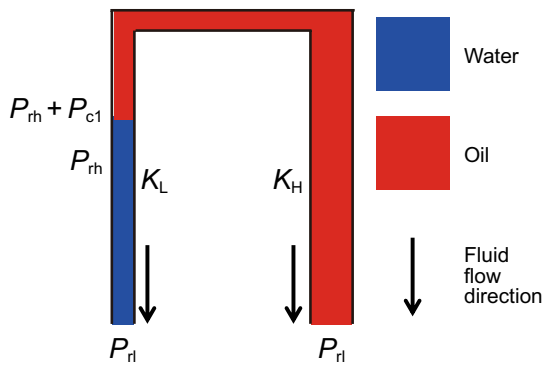

(d) Elastic energy release

Fig. 2 Sketch map of pressurizing-soaking-depressurizing process for counter-current imbibition scenario

seen from the above analysis, both imbibition and elastic energy have non-negligible contributions to oil production, so the capillary force, specific gravity, and compressibility of rock and fluids should be included. In tight/shale reservoirs, the rock fractured into discrete blocks around the wellbore is surrounded by the fracturing fluid or water, and the matrix block with its adjacent fractures are regarded as a unit. The oil can be displaced out from the matrix by imbibition, gravity, and pressure difference between matrix and fractures. Because the fractures are filled with proppants, they are regarded as highly permeable porous media. Therefore, the diffusivity equation of water can be written as

$\nabla \cdot\left[\frac{K K_{\mathrm{rw}} \rho_{\mathrm{w}}}{\mu_{\mathrm{w}}}\left(\nabla p_{\mathrm{w}}+\gamma_{\mathrm{w}} \nabla D\right)\right]+\delta_{\mathrm{w}} \rho_{\mathrm{w}} q_{\mathrm{w}}=\frac{\partial}{\partial t}\left(\rho_{\mathrm{w}} S_{\mathrm{w}} \phi\right)$.

The diffusivity equation of oil under both imbibition and pressure difference is $\nabla \cdot\left\{\frac{K K_{\mathrm{ro}} \rho_{\mathrm{o}}}{\mu_{\mathrm{o}}}\left[\nabla p_{\mathrm{w}}+\nabla p_{\mathrm{cow}}\left(S_{\mathrm{w}}\right)+\gamma_{\mathrm{o}} \nabla D\right]\right\}+\delta_{\mathrm{o}} \rho_{\mathrm{o}} q_{\mathrm{o}}=\frac{\partial}{\partial t}\left(\rho_{\mathrm{o}} S_{\mathrm{o}} \phi\right)$,

where $K$ is the absolute permeability; $K_{\mathrm{rw}}$ and $K_{\mathrm{ro}}$ are the relative permeability of water and oil, respectively; $\rho_{\mathrm{o}}$ and $\rho_{\mathrm{w}}$ are the density of oil and water, respectively; $\mu_{\mathrm{o}}$ and $\mu_{\mathrm{w}}$ are the viscosity of oil and water, respectively. $p_{\mathrm{w}}$ is the water phase pressure; $p_{\text {cow }}\left(S_{\mathrm{w}}\right)$ is the capillary pressure between oil and water at a certain water saturation; $\gamma_{\mathrm{o}}$ and $\gamma_{\mathrm{w}}$ are the gravity of oil and water, respectively; $D$ is the buried depth; $q_{\mathrm{o}}$ and $q_{\mathrm{w}}$ are the volume flow of source/sink term; $S_{\mathrm{o}}$ and $S_{\mathrm{w}}$ are the saturation of oil and water, respectively; $\phi$ is the porosity; $t$ is time; $\delta_{\mathrm{o}}$ and $\delta_{\mathrm{w}}$ are Haviside function of oil and water phase, respectively.

The auxiliary equations are as follows: 
$p_{\text {cow }}\left(S_{\mathrm{w}}\right)=p_{\mathrm{o}}-p_{\mathrm{w}}$,

$S_{\mathrm{o}}+S_{\mathrm{w}}=1$.

The compressibility of rock and fluid is the major source of elastic energy. The state equations of rock and fluid are as follows:

$\rho_{1}=\rho_{10} \mathrm{e}^{C_{1}\left(p_{1}-p_{0}\right)}$,

$\phi=\phi_{0}+C_{\mathrm{r}}\left(p_{1}-p_{0}\right)$,

where 1 represents the liquid phase (i.e., water or oil); $\rho_{10}$ is the density of phase 1 at reference pressure; $\phi_{0}$ is the porosity at reference pressure; $C_{1}$ is the compressibility of oil or water; $C_{\mathrm{r}}$ is the compressibility of rock; $p_{1}$ is the pressure of phase $1 ; p_{0}$ is the reference pressure.

As reported by Corey (1954), the relation between capillary force and water saturation can be approximately described as

$p_{\text {cow }}\left(S_{\mathrm{w}}\right)=C_{\mathrm{ow}} \sqrt{\frac{1}{S_{\mathrm{w}}}}$,

where $C_{\mathrm{ow}}$ is named as capillary index. To simplify the process, Eq. (7) can be written as

$p_{\text {cow }}\left(S_{\mathrm{w}}\right)=C_{\mathrm{ow}} \sqrt{\frac{1}{a \bar{S}_{\mathrm{w}}+b}}$,

where $\bar{S}_{\mathrm{w}}$ is the normalized water saturation

$\bar{S}_{\mathrm{w}}=\frac{S_{\mathrm{w}}-S_{\mathrm{wc}}}{1-S_{\mathrm{or}}-S_{\mathrm{wc}}}$,

where $S_{\mathrm{wc}}$ is the connate water saturation; $S_{\mathrm{or}}$ is the residual oil saturation; $a=1-S_{\mathrm{or}}-S_{\mathrm{wc}}$ and $b=S_{\mathrm{wc}}$.

Generally, some of tight oil reservoirs are water-wet, so imbibition can happen even if there is no surfactant in the fracturing fluid. However, in some mixed-wet or oil-wet reservoirs, surfactant is usually added into water or the fracturing fluid to promote imbibition by changing the wettability (Begum et al. 2017; Alvarez et al. 2017; Meng et al. 2018; Huang et al. 2020). In order to reflect this effect, the capillary force ratio of water to surfactant can be approximated using the Young-Laplace equation assuming constant pore diameter for water and surfactant imbibition,

$p_{\mathrm{cos}}=\frac{p_{\mathrm{cow}} \sigma_{\mathrm{os}} \cos \theta_{\mathrm{os}}}{\sigma_{\mathrm{ow}} \cos \theta_{\mathrm{ow}}}$,

where $p_{\cos }$ is the capillary force between oil and surfactant; $\sigma_{\mathrm{ow}}$ is the interficial tension (IFT) between oil and water; $\sigma_{\mathrm{os}}$ is the IFT between oil and surfactant; $\theta_{\mathrm{ow}}$ is the contact angle between oil and water; $\theta_{\mathrm{os}}$ is the contact angle between oil and surfactant.

Besides, the capillary force is significantly related to the properties of porous media (Habibi et al. 2015). Hence, the capillary force ratio in different porous media for the same fluid is

$p_{\text {cow }}(K, \phi)=p_{\text {cowref }} \sqrt{\frac{\phi K_{\text {ref }}}{\phi_{\text {ref }} K}}$,

where $p_{\text {cowref }}$ is the capillary force between oil and water in reference media; $K_{\text {ref }}$ and $\phi_{\text {ref }}$ are the permeability and porosity of referenced media, respectively.

Combining Eqs. (10) and (11), the ratio of the capillary index for different systems is

$C_{\mathrm{os}}=\frac{C_{\mathrm{ow}} \sigma_{\mathrm{os}} \cos \theta_{\mathrm{os}}}{\sigma_{\mathrm{ow}} \cos \theta_{\mathrm{ow}}}$,

where $C_{\mathrm{ow}}$ is the capillary index for the oil-water system; $C_{\mathrm{os}}$ is the capillary index for the oil-surfactant system.

Analogously, the ratio of the capillary index for water imbibition in different media is

$C_{\text {ow }}(K, \phi)=C_{\text {owref }} \sqrt{\frac{\phi K_{\text {ref }}}{\phi_{\text {ref }} K}}$,

where $C_{\text {owref }}$ is the capillary index for the oil-water system in referenced media.

The impacts of surfactant in any porous media can be included by combining Eqs. (12) and (13):

$C_{\mathrm{os}}=C_{\mathrm{owref}} \frac{\sigma_{\mathrm{os}} \cos \theta_{\mathrm{os}}}{\sigma_{\mathrm{ow}} \cos \theta_{\mathrm{ow}}} \sqrt{\frac{\phi K_{\mathrm{ref}}}{\phi_{\mathrm{ref}} K}}$.

The added surfactant also affects the residual oil saturation by changing IFT. Because the flow rate is very low for imbibition, the relation between the residual oil saturation and IFT can be simplified to the following form

$S_{\text {or }}=\frac{S_{\text {orw }}}{1+\psi / \sigma_{\text {ow }}}$.

Here, $S_{\text {orw }}$ and $\psi$ can be attained by matching the experimental data.

Another important parameter for imbibition is the relative permeability. The added surfactant will affect the relative permeability by changing the residual oil saturation (Babadagli 2003; Lu et al. 2014; Goudarzi et al. 2015). Referring to the relative permeability formula of wetting and non-wetting phases achieved by Burdine (1953) and combining Eq. (8), the relative permeability equations for the oil-water system can be obtained by integration, 
$K_{\mathrm{rw}}=K_{\mathrm{rwor}} \frac{\bar{S}_{\mathrm{w}}^{2}\left(a \bar{S}_{\mathrm{w}}^{2}+2 b \bar{S}_{\mathrm{w}}\right)}{a+2 b}$,

$K_{\text {ro }}=K_{\text {rowc }} \frac{\left(1-\bar{S}_{\mathrm{w}}\right)^{2}\left(a+2 b-a \bar{S}_{\mathrm{w}}^{2}-2 b \bar{S}_{\mathrm{w}}\right)}{a+2 b}$,

where $K_{\text {rwor }}$ is the water-phase relative permeability at residual oil saturation; $K_{\text {rowc }}$ is the oil-phase relative permeability at connate water saturation. Because $a$ and $b$ are the functions of residual oil and connate water saturation, the impact of surfactant on relative permeability is included.

\section{Solution and validation}

\subsection{Solution method}

In this work, the IMPES method is used to solve the pressure and saturation equations. Combining Eqs. (1) and (2), the following equation is achieved:

$$
\begin{gathered}
\frac{1}{\rho_{\mathrm{w}}} \nabla \cdot\left\{\frac{K K_{\mathrm{rw}} \rho_{\mathrm{w}}}{\mu_{\mathrm{w}}}\left[\nabla p_{\mathrm{o}}-\nabla p_{\mathrm{cow}}\left(S_{\mathrm{w}}\right)+\gamma_{\mathrm{w}} \nabla D\right]\right\}+\delta_{\mathrm{w}} q_{\mathrm{w}}+ \\
\frac{1}{\rho_{\mathrm{o}}} \nabla \cdot\left[\frac{K K_{\mathrm{ro}} \rho_{\mathrm{o}}}{\mu_{\mathrm{o}}}\left(\nabla p_{\mathrm{o}}+\gamma_{\mathrm{o}} \nabla D\right)\right]+\delta_{\mathrm{o}} q_{\mathrm{o}}=\phi c_{\mathrm{t}} \frac{\partial p_{\mathrm{o}}}{\partial t}
\end{gathered}
$$

with

$c_{\mathrm{t}}=c_{\mathrm{p}}+c_{\mathrm{o}} S_{\mathrm{o}}+c_{\mathrm{w}} S_{\mathrm{w}}$,

$c_{\mathrm{p}}=\frac{1}{\phi} \frac{\partial \phi}{\partial p_{\mathrm{o}}}$,

$c_{\mathrm{o}}=\frac{1}{\rho_{\mathrm{o}}} \frac{\partial \rho_{\mathrm{o}}}{\partial p_{\mathrm{o}}}$

$c_{\mathrm{w}}=\frac{1}{\rho_{\mathrm{w}}} \frac{\partial \rho_{\mathrm{w}}}{\partial p_{\mathrm{o}}}$. with

$V_{\mathrm{p}}=V_{\mathrm{b}} \phi$,

$Q_{\mathrm{w}}=V_{\mathrm{b}} q_{\mathrm{w}}$

$Q_{\mathrm{o}}=V_{\mathrm{b}} q_{\mathrm{o}}$.

Thus, the pressure equation in terms of the oil phase pressure $p_{\mathrm{o}}$ is:

$a_{i, j, k} p_{\mathrm{o} i-1, j, k}^{n+1}+c_{i, j, k} p_{\mathrm{o} i, j-1, k}^{n+1}+e_{i, j, k} p_{\mathrm{o} i, j, k-1}^{n+1}+g_{i, j, k} p_{\mathrm{o} i, j, k}^{n+1}$

$+b_{i, j, k} p_{\mathrm{oit1,j,k}}^{n+1}+d_{i, j, k} p_{\mathrm{o} i, j+1, k}^{n+1}+f_{i, j, k} p_{\mathrm{o} i, j, k+1}^{n+1}=h_{i, j, k}$

with

$a_{i, j, k}=\frac{T_{\mathrm{w} i-\frac{1}{2}, j, k}}{\rho_{\mathrm{w} i, j, k}}+\frac{T_{\mathrm{o} i-\frac{1}{2}, j, k}}{\rho_{\mathrm{o} i, j, k}}$,

$b_{i, j, k}=\frac{T_{\mathrm{w} i+\frac{1}{2}, j, k}}{\rho_{\mathrm{w} i, j, k}}+\frac{T_{\mathrm{o} i+\frac{1}{2}, j, k}}{\rho_{\mathrm{o} i, j, k}}$,

$c_{i, j, k}=\frac{T_{\mathrm{w} i, j-\frac{1}{2}, k}}{\rho_{\mathrm{w} i, j, k}}+\frac{T_{\mathrm{o} i, j-\frac{1}{2}, k}}{\rho_{\mathrm{o} i, j, k}}$,

$d_{i, j, k}=\frac{T_{\mathrm{w} i, j+\frac{1}{2}, k}}{\rho_{\mathrm{w} i, j, k}}+\frac{T_{\mathrm{o} i, j+\frac{1}{2}, k}}{\rho_{\mathrm{o} i, j, k}}$,

$e_{i, j, k}=\frac{T_{\mathrm{w} i, j, k-\frac{1}{2}}}{\rho_{\mathrm{w} i, j, k}}+\frac{T_{\mathrm{o} i, j, k-\frac{1}{2}}}{\rho_{\mathrm{o} i, j, k}}$,

$f_{i, j, k}=\frac{T_{\mathrm{w} i, j, k+\frac{1}{2}}}{\rho_{\mathrm{w} i, j, k}}+\frac{T_{\mathrm{o} i, j, k+\frac{1}{2}}}{\rho_{\mathrm{o} i, j, k}}$,

$g_{i, j, k}=-\left[a_{i, j, k}+b_{i, j, k}+c_{i, j, k}+d_{i, j, k}+e_{i, j, k}+f_{i, j, k}+\left(V_{\mathrm{p}} c_{\mathrm{t}}\right)_{i, j, k} / \Delta t\right]$,

Euler differential method is applied to establish the difference scheme,

$\frac{1}{\rho_{\mathrm{w}}} \Delta T_{\mathrm{w}} \Delta\left(p_{\mathrm{o}}-p_{\text {cow }}+\gamma_{\mathrm{w}} D\right)+\delta_{\mathrm{w}} Q_{\mathrm{w}}+\frac{1}{\rho_{\mathrm{o}}} \Delta T_{\mathrm{o}} \Delta\left(p_{\mathrm{o}}+\gamma_{\mathrm{o}} D\right)+\delta_{\mathrm{o}} Q_{\mathrm{o}}=\frac{\left(V_{\mathrm{p}} c_{\mathrm{t}}\right)^{n}}{\Delta t}\left(p_{\mathrm{o}}^{n+1}-p_{\mathrm{o}}^{n}\right)$ 


$$
\begin{aligned}
h_{i, j, k}= & -\frac{\Delta\left(T_{\mathrm{w}} \Delta p_{\mathrm{cow}}\right)_{i, j, k}+\Delta\left(T_{\mathrm{w}} \gamma_{\mathrm{w}} \Delta D\right)_{i, j, k}+\delta_{\mathrm{w} i, j, k} Q_{\mathrm{w} i, j, k}}{\rho_{\mathrm{w} i, j, k}} \\
& -\frac{\delta_{\mathrm{o} i, j, k} Q_{\mathrm{o} i, j, k}+\Delta\left(T_{\mathrm{o}} \gamma_{\mathrm{o}} \Delta D\right)_{i, j, k}}{\rho_{\mathrm{o} i, j, k}}-\frac{\left(V_{\mathrm{p}} c_{\mathrm{t}}\right)_{i, j, k}}{\Delta t} p_{\mathrm{o} i, j, k}^{n},
\end{aligned}
$$$$
T_{l i \pm \frac{1}{2}, j, k}=\frac{(A K)_{i \pm \frac{1}{2}, j, k}}{\Delta x_{i \pm \frac{1}{2}, j, k}}\left(\frac{K_{\mathrm{rl}} \rho_{1}}{\mu_{1}}\right)_{i \pm \frac{1}{2}, j, k},
$$$$
T_{1 i, j \pm \frac{1}{2}, k}=\frac{(A K)_{i, j \pm \frac{1}{2}, k}}{\Delta y_{i, j \pm \frac{1}{2}, k}}\left(\frac{K_{\mathrm{rl}} \rho_{1}}{\mu_{1}}\right)_{i, j \pm \frac{1}{2}, k},
$$$$
T_{1 i, j, k \pm \frac{1}{2}}=\frac{(A K)_{i, j, k \pm \frac{1}{2}}}{\Delta z_{i, j, k \pm \frac{1}{2}}}\left(\frac{K_{\mathrm{rl}} \rho_{1}}{\mu_{1}}\right)_{i, j, k \pm \frac{1}{2}} .
$$

The difference equation of the oil phase is as follows:

$$
\Delta\left(T_{\mathrm{o}}^{n} \Delta p_{\mathrm{o}}^{n+1}\right)_{i, j, k}+\delta_{\mathrm{o}}^{n} Q_{\mathrm{o} i, j, k}^{n}=\frac{1}{\Delta t}\left[\left(V_{\mathrm{p}} S_{\mathrm{o}} \rho_{\mathrm{o}}\right)^{n+1}-\left(V_{\mathrm{p}} S_{\mathrm{o}} \rho_{\mathrm{o}}\right)^{n}\right]_{i, j, k}
$$

Based on Eq. (21), the oil saturation is achieved, and then, the water saturation is obtained by Eq. (4).

\subsection{Validation of the numerical model}

In order to verify the reliability of the simulation model, we choose a well of J Oilfield in China to simulate highpressure soaking and depressurizing production. J Oilfield is a typical terrestrial reservoir. The reservoir depth is about 2000-4000 m with an effective thickness of 10-30 m. Natural fractures are not well developed, and the dissolved gas-oil ratio is very low. The formation pressure gradient is

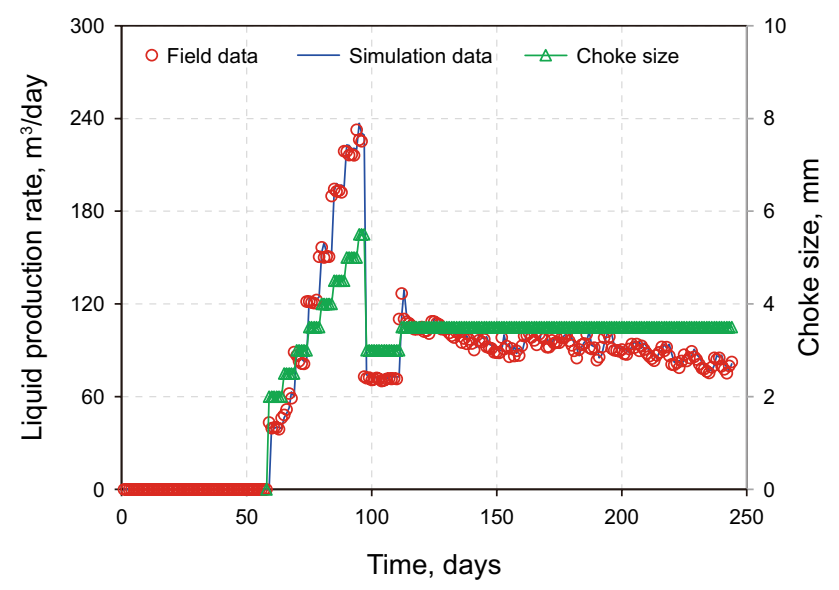

Fig. 3 The specific liquid production rates and choke sizes at different times around $1.0-1.3 \mathrm{MPa} / 100 \mathrm{~m}$. The permeability is $0.001-0.1$ $\mathrm{mD}$, and the oil viscosity is several to tens centipoises. The wettability is neutral-wet to slightly oil-wet, and water sensitivity is weak. Multistage fracturing was performed in horizontal well with cement plug. The development effect of depletion drive is not ideal in the pilot. Therefore, highpressure soaking with fracturing fluid after hydraulic fracturing has been conducted in this oilfield.

JHW023 is the pilot well for high-pressure soaking in J Oilfield, and the oil production is much higher than the previous wells. The length of the horizontal well is $1,246 \mathrm{~m}$, and it is fractured with $37,408 \mathrm{~m}^{3}$ of fracturing fluid. The fracturing rate reaches up to $14-15 \mathrm{~m}^{3} / \mathrm{min}$. The fracturing pressure is around $70-75 \mathrm{MPa}$. After fracturing, it was soaked for about 60 days under high-pressure conditions, then different chokes were employed for depletion drive. Oil and water production rates are recorded; thus, constant liquid production rates can be used to match the oil production rates and water-cut, as shown in Fig. 3. The parameters of JHW023 and oil reservoir are shown in Table 1 . The reservoir and fluid parameters come from the oilfield and laboratory. The parameters of hydraulic fractures, relative permeability, and compressibility are obtained by matching the practical data. During the simulation process, about $37,400 \mathrm{~m}^{3}$ water were injected into the reservoir by a horizontal well with 81 cluster of hydraulic fractures at first. Then, high-pressure soaking were followed for about 60 days. After that, depletion drive was carried out. The BHP and production data of

Table 1 Parameters used for simulation of Well JHW023 in J Oilfield

\begin{tabular}{ll}
\hline Parameter & Value \\
\hline Well length, m & 1246 \\
Pay thickness, m & 16.5 \\
Reservoir pressure, MPa & 38.5 \\
Number of fractures & 81 \\
Porosity, $\%$ & 14.7 \\
Matrix permeability, mD & 0.08 \\
Initial oil saturation & 0.7 \\
Formation oil viscosity, mPa s & 5.0 \\
Formation oil density, g/cm ${ }^{3}$ & 0.88 \\
Fracture half length, $\mathrm{m}$ & 135 \\
Fracture permeability, $\mathrm{mD}$ & 7500 \\
$K_{\mathrm{rwor}}$ & 0.55 \\
$K_{\text {rowc }}$ & 1.0 \\
$C_{\mathrm{ow}}$ & 1500 \\
$S_{\mathrm{wc}}$ & 0.3 \\
$S_{\text {or }}$ & 0.3 \\
$C_{\mathrm{r}}, \mathrm{MPa}^{-1}$ & 0.0005 \\
$C_{\mathrm{o}}, \mathrm{MPa}^{-1}$ & 0.0006 \\
$C_{\mathrm{w}}, \mathrm{MPa}^{-1}$ & 0.0006 \\
\hline
\end{tabular}




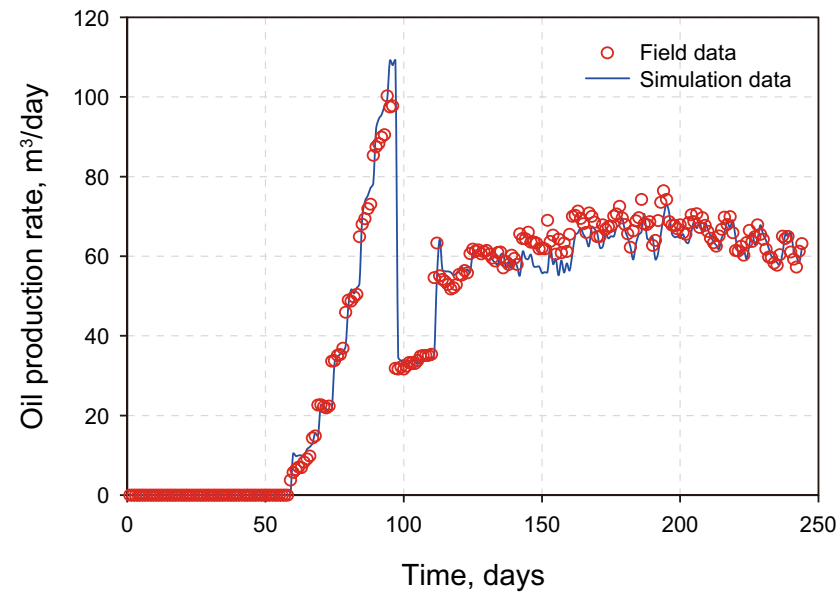

(a) Oil production rate

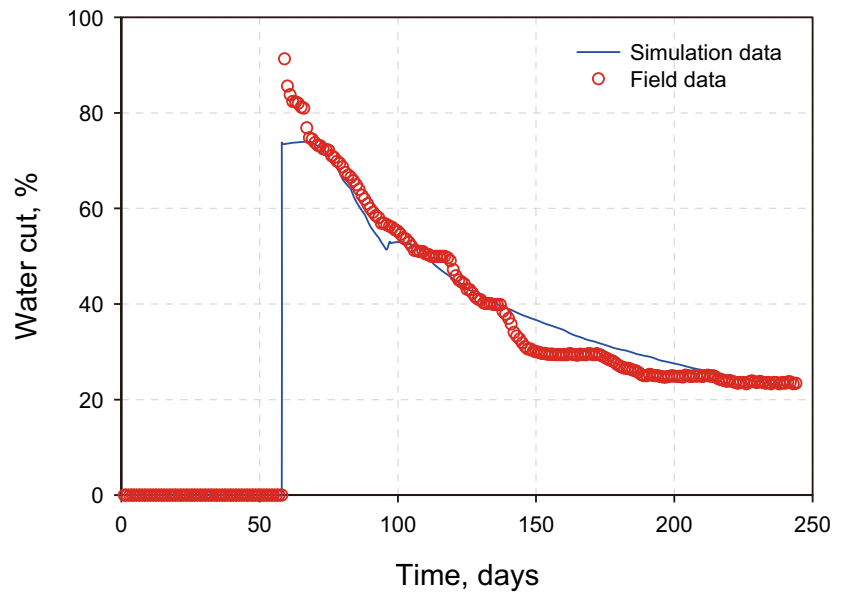

(b) Water cut

Fig. 4 Comparisons of oil production rate and water-cut between field data and simulation

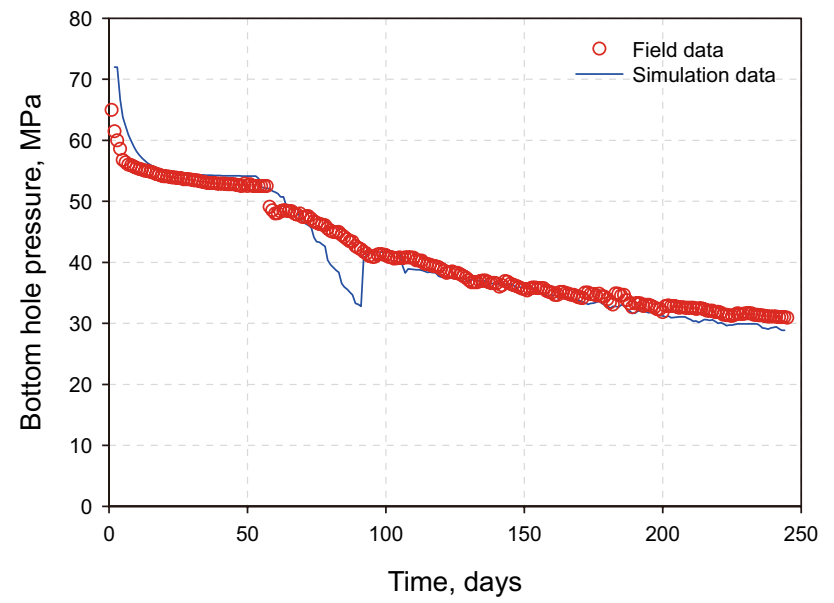

Fig. 5 Comparisons of bottom hole pressure between field data and simulation

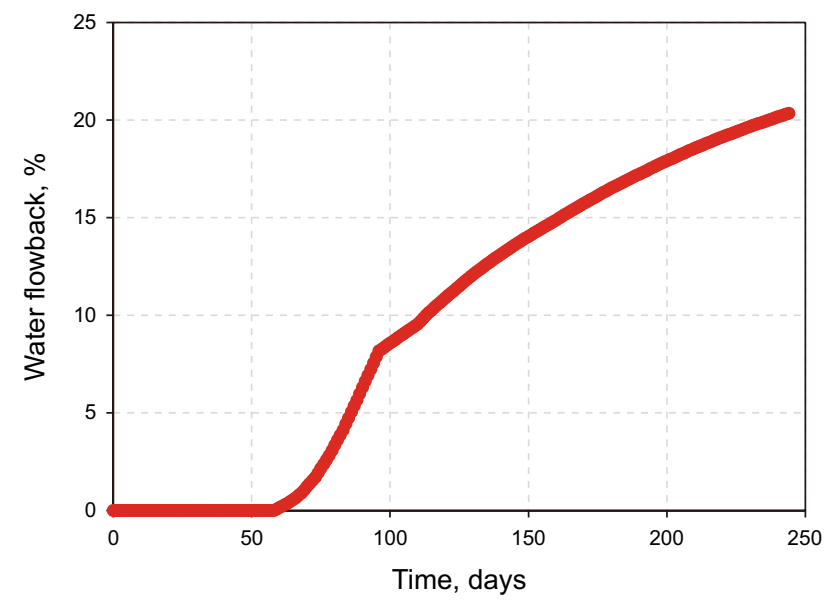

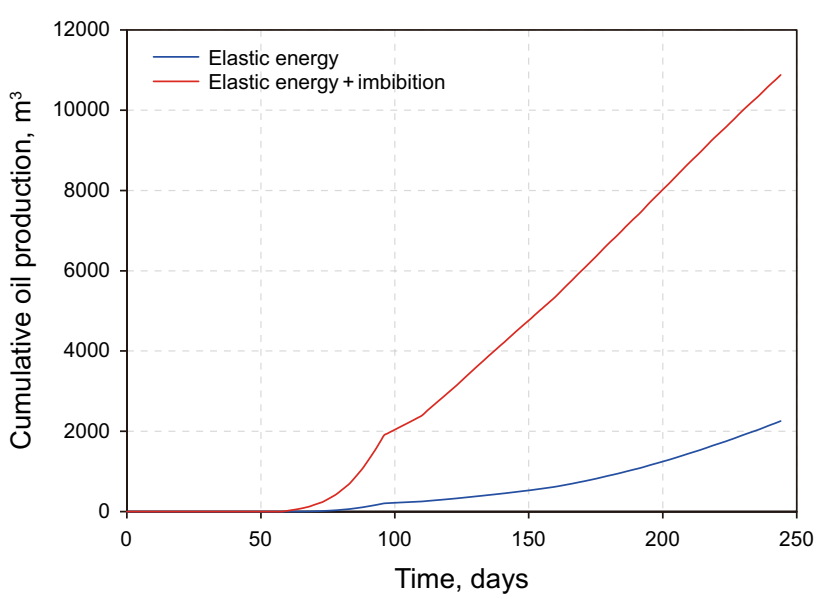

Fig. 7 Cumulative oil productions of different scenarios

high-pressure soaking and depletion drive stages were monitored and used to match the simulation results. Figures 4 and 5 show comparisons of oil production rate, water-cut, and BHP between field data and simulation results. We can see that the simulation results have a good agreement with the field data. Figure 6 shows the flowback percentage of the injected water. It is clear that only $20 \%$ of the fracturing fluid flows back after producing for six months, which agrees well with the typical data found in literature (King 2010). We also used the fitted model to study the contributions of imbibition and elastic energy. Figure 7 demonstrates the cumulative oil production of the scenarios with/without imbibition. Based on the data, the contributions of elasticity and imbibition are about $20 \%$ and $80 \%$, respectively.

Fig. 6 Backflow percentage of the injected fracturing fluid 


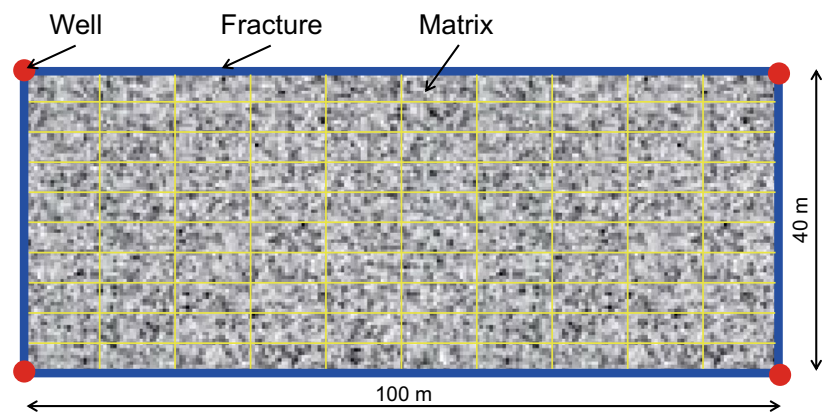

Fig. 8 Schematic diagram of the gridding system and well placement in the typical unit

Table 2 Parameters used in simulation cases

\begin{tabular}{ll}
\hline Parameter & Value \\
\hline Grid number for matrix $\left(N_{x} \times N_{y} \times N_{z}\right)$ & $10 \times 10 \times 5$ \\
Matrix permeability, mD & 0.08 \\
Porosity, \% & 14.7 \\
Oil saturation in matrix & 0.7 \\
Oil viscosity, mPa s & 6.0 \\
Oil density, g/cm ${ }^{3}$ & 0.88 \\
Initial reservoir pressure in the matrix, $\mathrm{MPa}$ & 30 \\
Pressure in fractures after fracturing, MPa & 70 \\
Soaking time, days & 60 \\
$C_{\mathrm{r}}, \mathrm{MPa}^{-1}$ & 0.0005 \\
$C_{\mathrm{o}}, \mathrm{MPa}^{-1}$ & 0.0006 \\
$C_{\mathrm{w}}, \mathrm{MPa}^{-1}$ & 0.0006 \\
$C_{\mathrm{ow}}$ & 1500 \\
\hline
\end{tabular}

\section{Results and discussion}

\subsection{Model applications}

On the basis of oilfield production data, the injected water was retained in the reservoir. Smaller flowback percentage of the fracturing fluid indicates a better production (Abbasi et al. 2012; Williams-Kovacs et al. 2015; Cao et al. 2017). As mentioned, high-pressure soaking plays an important role in the fracturing fluid backflow. In order to clearly understand the significances of high-pressure soaking, the contributions of different mechanisms, the optimal soaking times, and the huff-n-puff performances, an ideal model based on the average values in J Oilfield is employed to conduct simulations.

The formation thickness is $15 \mathrm{~m}$. The fracture spacing and fracture half-length used in the simulation are $40 \mathrm{~m}$ and $100 \mathrm{~m}$, respectively. Therefore, a typical unit was taken from the fractured tight reservoir. Because the fracture conductivity is very high, the distribution of the injected or produced fluid in fractures is almost uniform. Therefore, the gridding system and well placement are as shown in Fig. 8. The initial reservoir pressure is $30 \mathrm{MPa}$, and the fracturing pressure is $70 \mathrm{MPa}$, which means the initial pressure in fractures is $70 \mathrm{MPa}$ after fracturing. The initial oil saturation in matrix and fractures are 0.70 and 0.25 , respectively. We assume that the matrix block is cut into a cuboid by the fractures, which are full of the fracturing fluid or surfactant solution. The maximum BHP is set as $70 \mathrm{MPa}$ for injecting water, and the $\mathrm{BHP}$ is set as $15 \mathrm{MPa}$ for production. The other parameters used in the simulation cases are from the fitted model in Sect. 4 and listed in Table 2. The parameters of sensitivity analysis are shown in Table 3.

\subsubsection{Significances of high-pressure soaking}

In this section, we aimed to observe the significances of high-pressure soaking by comparing the production performances, pressure propagation, and fluid movement in different scenarios. Because the wettability of most tight rocks is mixed-wet or slightly oil-wet, the performances of highpressure soaking for both water-wet and mixed-wet scenarios are compared as well. Figure 9 shows the comparisons of production performances of water-wet rock without soaking, water-wet rock with soaking, and mixed-wet with soaking. From Fig. 9a, the oil recovery of the rock without soaking is $1.82 \%$, and it is the lowest. The oil recovery for mixedwet rock with high-pressure soaking for 60 days is $2.88 \%$ and that for water-wet rock with high-pressure soaking for 60 days is $4.02 \%$. As the results indicate, high-pressure soaking turns out very significant. For the water-wet rock without soaking, there is no enough time for imbibition and pressure propagation, and thus, less oil is expelled by imbibition and

Table 3 Parameters for operational sensitivity

\begin{tabular}{lllllll}
\hline Parameter & Level 1 & Level 2 & Level 3 & Level 4 & Level 5 & Level 6 \\
\hline Oil viscosity, mPa s & 1 & 3 & 5 & 7 & 9 & - \\
BHP, MPa & 5 & 10 & 15 & 5 & 20 & 30 \\
IFT, mN/m & 0.1 & 0.05 & 0.08 & 0.1 & 30 & 0.5 \\
Permeability, $\mathrm{mD}$ & 0.01 & 1 & 0.4 & 0.2 & 0.1 & - \\
Specific surface area, $\mathrm{m}^{2} / \mathrm{m}^{3}$ & 2 & &
\end{tabular}




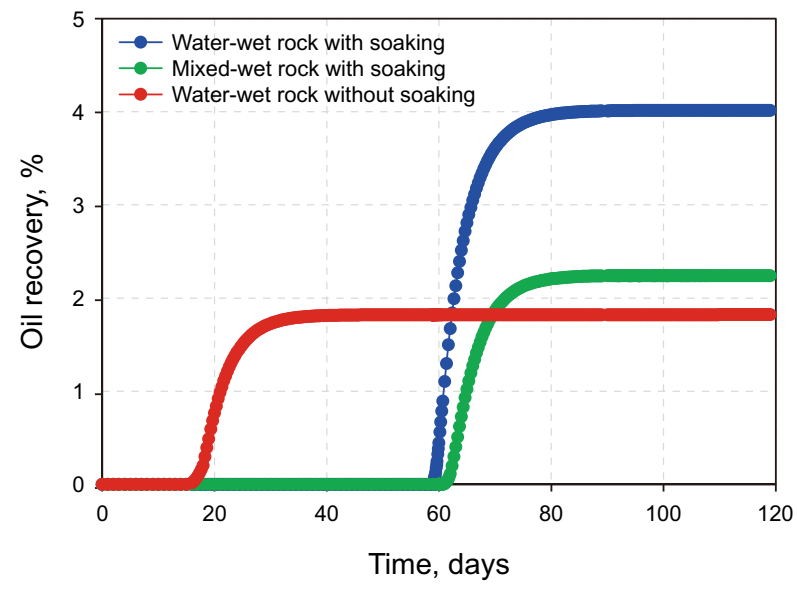

(a) Oil recovery

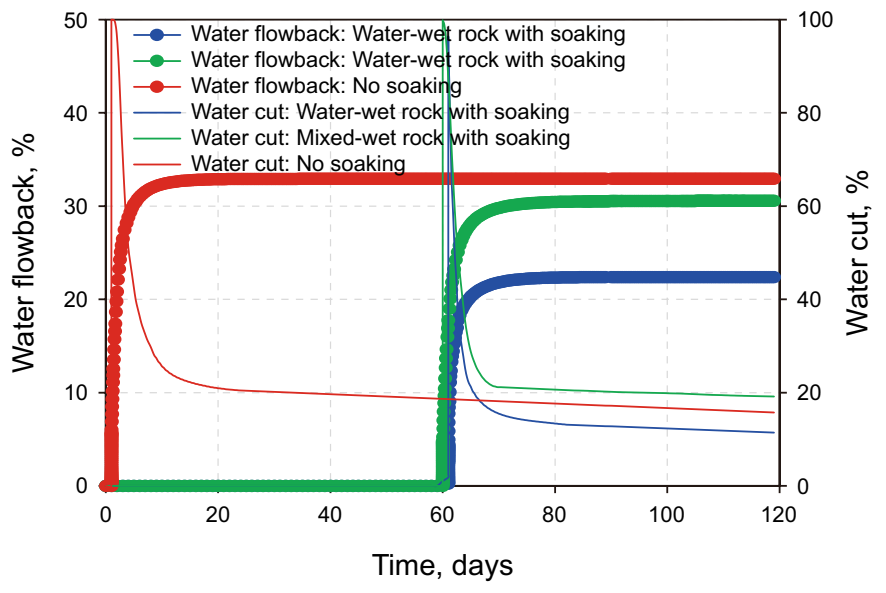

(b) Cumulative water production and water cut

Fig. 9 Comparisons of production performances with and without soaking for 60 days

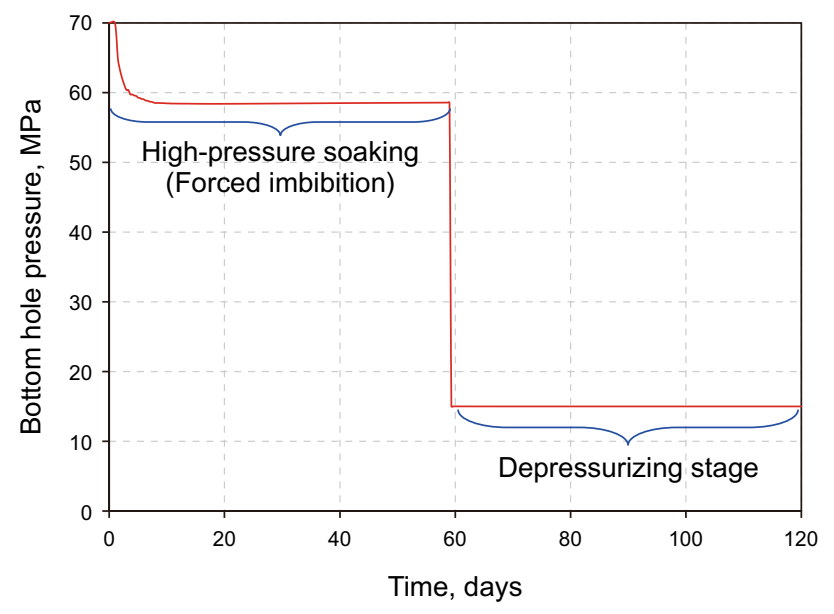

Fig. 10 Variations of BHP at the stages of soaking and depressurizing production

elastic energy. For the mixed-wet rock with high-pressure soaking, despite no imbibition occurring due to the adverse wettability, there is enough time for pressure propagation and more oil is expelled at depressurizing stage. For the water-wet rock with high-pressure soaking, both imbibition and pressure propagation play a part in increasing elastic energy, so the most oil is expelled. Figure $9 \mathrm{~b}$ shows the water-cut and water backflow in different scenarios. We can see that the water-cut is as high as $100 \%$ initially for the case without soaking, and the water backflow percentage reaches about $33 \%$. However, if it is soaked for 60 days, the watercut is lower and sharply reduces. The backflow percentages of mixed-wet and water-wet rocks are $30.5 \%$ and $22.4 \%$, respectively. Thus again, more water can enter the matrix to expel the oil out by high-pressure soaking.
Despite the mechanisms can be speculated from laboratory and field experiments, we also demonstrated the visual comparisons of pressure and saturation in the whole process. Figure 10 indicates the variations of BHP during high-pressure soaking and depressurizing production. It is clear that BHP decreases rapidly at the initial stage of soaking. The balanced pressure, about $58 \mathrm{MPa}$, is reached after soaking for about 10 days. The variations of pressure distribution in the matrix from the initial state to depressurizing production stage are shown in Fig. 11. The pressure propagation mainly occurs in the first 8 days. After high-pressure soaking, the pore pressure in the matrix is much higher than the initial reservoir pressure, so the elastic energy significantly increases.

Figure 12 shows the variations of oil saturation in different regions during high-pressure soaking. The oil saturation always increases in fractures, but decreases rapidly in the matrix surface firstly and then changes slightly. The water saturation in the matrix center mainly changes on the side. Figure 13 demonstrates the variations of the mean water saturation in the fracture and matrix surface. From Fig. 13a, we can see that the variations of the mean water saturation show different features in fractures at different stages. At the high-pressure soaking stage, the water saturation gradually decreases because water enters the matrix to expel out the oil by imbibition. At the depressurizing production stage, the mean water saturation decreases sharply and then slowly because the water in fractures is easier to flow into the well. Because water enters the matrix under the high-pressure gradient, the mean water saturation increases fast in the matrix surface at first, which is corresponding to the pressurizing stage in Figs. 1b, 10, and 11. Then, the mean water saturation slowly increases during soaking, which is corresponding to high-pressure soaking in Fig. 1c. Afterwards, the mean 


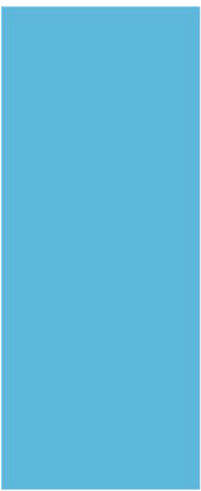

$t=0$ day

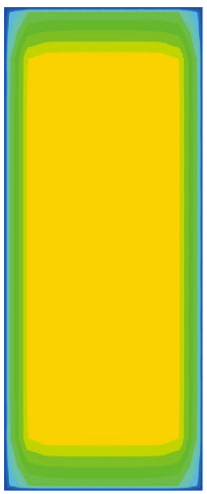

$t=60$ days

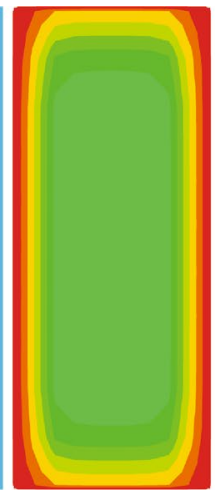

$t=1$ day

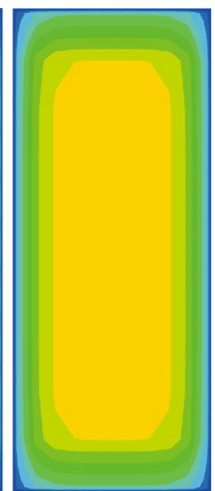

$t=61$ days

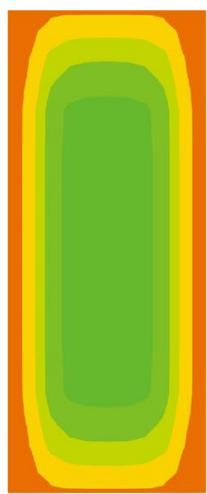

$t=2$ days

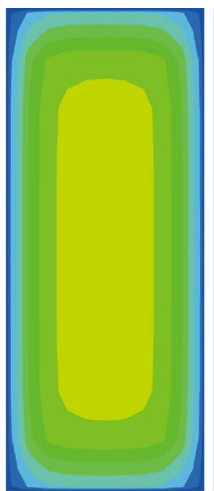

$t=62$ days

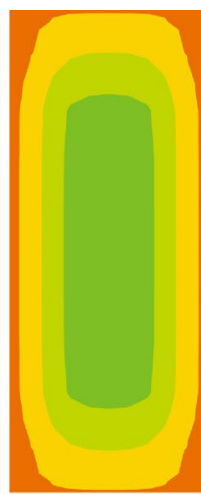

$t=3$ days

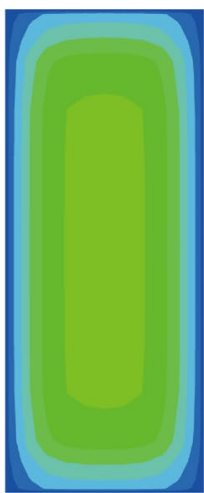

$t=63$ days

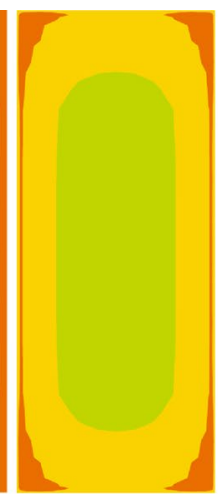

$t=4$ days

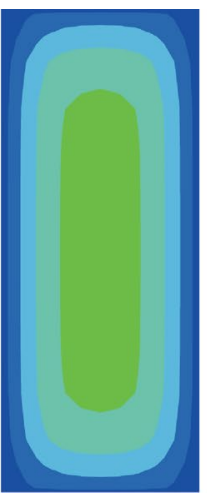

$t=65$ days

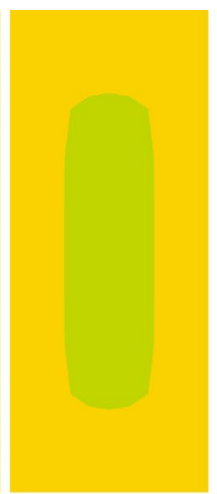

$t=5$ days

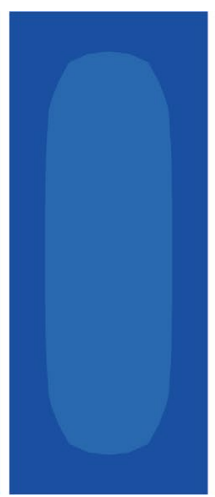

$t=70$ days

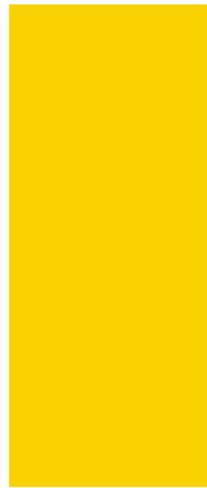

Pressure, $\mathrm{MPa}$

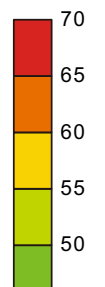

$t=8$ days

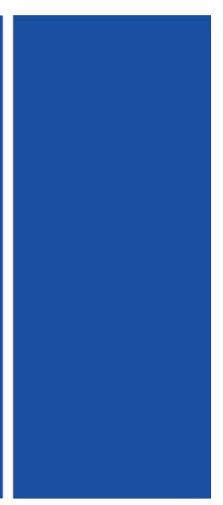

$t=75$ days

Fig. 11 Variations of the pressure distributions in the whole process (unit: MPa)

water saturation shows a small jump at the beginning of depressurizing production and then does not change anymore. The "jump" indicates more oil flows out than water, which is corresponding to the analysis of depressurizing stage in Fig. 1d. These visible maps and statistic data well support the previous inferences.

\subsubsection{Contributions of different mechanisms}

As the previous analysis, elastic energy and imbibition are the main mechanisms of oil production for high-pressure soaking. In the above simulations, we preliminarily analyzed the contributions of elastic energy and imbibition. In this section, we particularly investigated the impacts of the acting forces on oil production. The acting forces during elastic drive include gravity and elastic force. The acting forces during imbibition include gravity and capillary force. Therefore, four cases were conducted. The contribution of elastic force caused by pressure change is observed in Case 1 . The contribution of both gravity and elastic force are included in Case 2, so the contribution of gravity could be obtained from the difference between Cases 1 and 2. The contribution of both capillary force and elastic force is included in Case 3, so the contribution of capillary force could be obtained from the difference between Cases 1 and 3. The contributions of both elastic drive and imbibition are included in Case 4 by considering the gravity, capillary, and elastic force, so the contribution of gravity to both elastic drive and imbibition could be obtained from the difference between Cases 3 and 4. Correspondingly, the contribution of gravity to imbibition can be observed from the differences among Cases 1-4. Figure 14 shows the cumulative oil production in different scenarios. We can see that the cumulative oil production of Case 2 is lower than that of Case 1, which indicates that gravity plays a slightly negative role in elastic drive. The reason is that the gravitational differentiation makes the water separate from oil in the fractures, and water is much easier to flow into the wellbore. The cumulative oil production of Case 3 is much larger than that of Case 1, which means the capillary force has a significant contribution through imbibition. Case 4 is very close to Case 3 , which seemingly means gravity has no impact on high-pressure soaking. In fact, the positive role of gravity in oil production by imbibition counteracts its negative role in oil production by elastic drive. In summary, the capillary force plays a dominant role in imbibition, pressure dominates elastic drive, and gravity has slight impacts on both imbibition and elastic drive. 


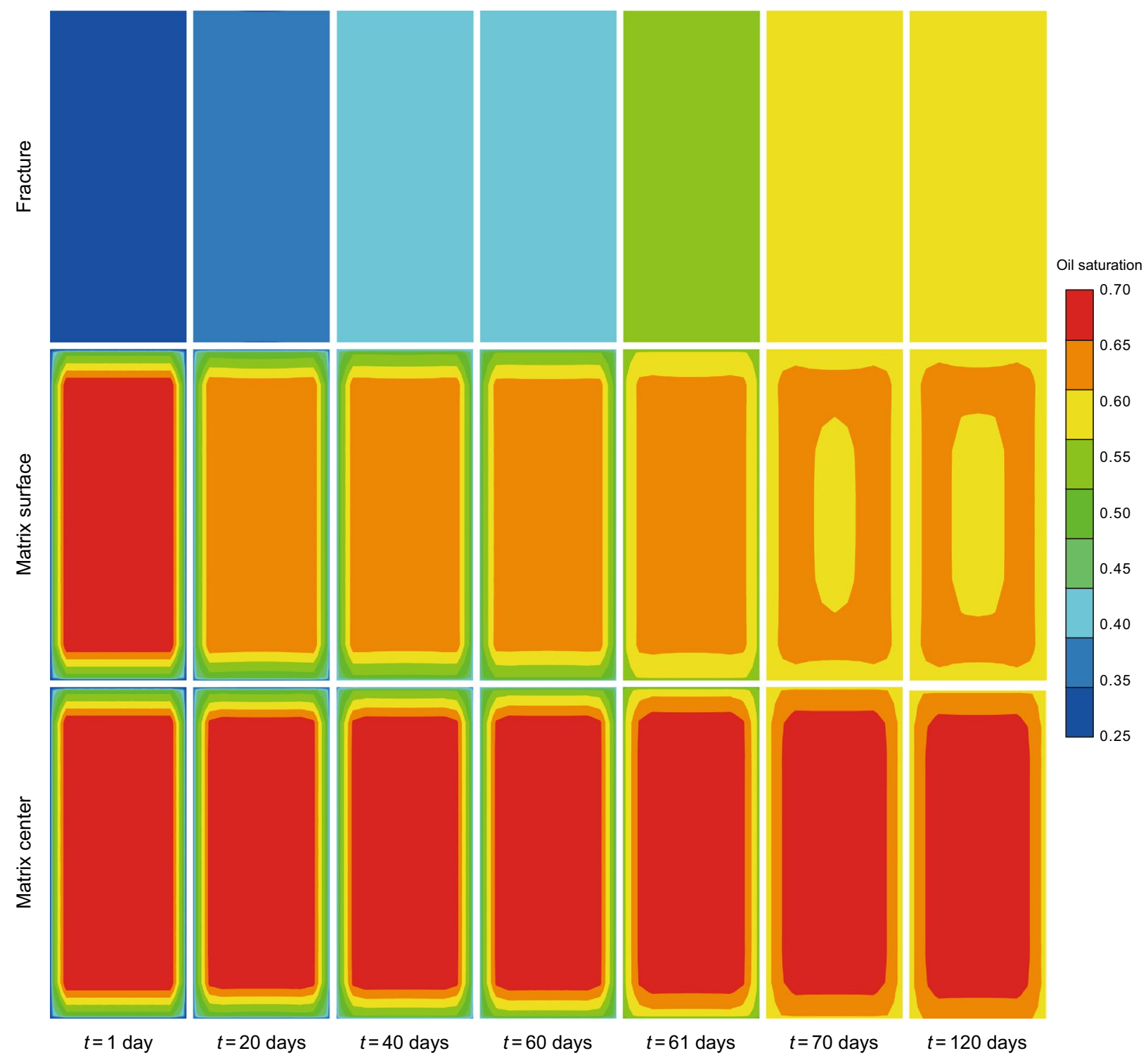

Fig. 12 Variations of the distribution of oil saturation in different locations during high-pressure soaking

Henceforth, we studied the impacts of oil viscosity, BHP, IFT, matrix permeability, and specific surface area on the contributions of different mechanisms, which are shown in Figs. 15, 16, 17, 18 and 19. From Fig. 15, oil viscosity has a slight impact on the contribution, since the increase in oil viscosity is unfavorable to both imbibition and elastic drive. Generally, the contribution of elastic energy increases as the oil viscosity increases. From Fig. 16, the contribution of elastic energy significantly decreases as the BHP increases. Elastic energy is dominated by the pressure difference, which has less impact on imbibition. As observed in Fig. 17, the contribution of elastic energy decreases as the IFT increases. The reason is that when the IFT is low, the capillary force is extremely low, so imbibition is very weak. As observed in Fig. 18, the contribution of elastic energy first increases as the matrix permeability increases and then decreases. Generally, the matrix permeability has a slight impact on the contribution. When the permeability is low, both the capillary force and the flow resistance are high, so imbibition contributes more than elastic energy. However, as the permeability increases, the capillary force decreases, so imbibition contributes less than elastic energy. From Fig. 19, the contribution of imbibition increases as the specific surface area increases. That is because larger specific surface area provides relatively larger contact area to conduct imbibition. 


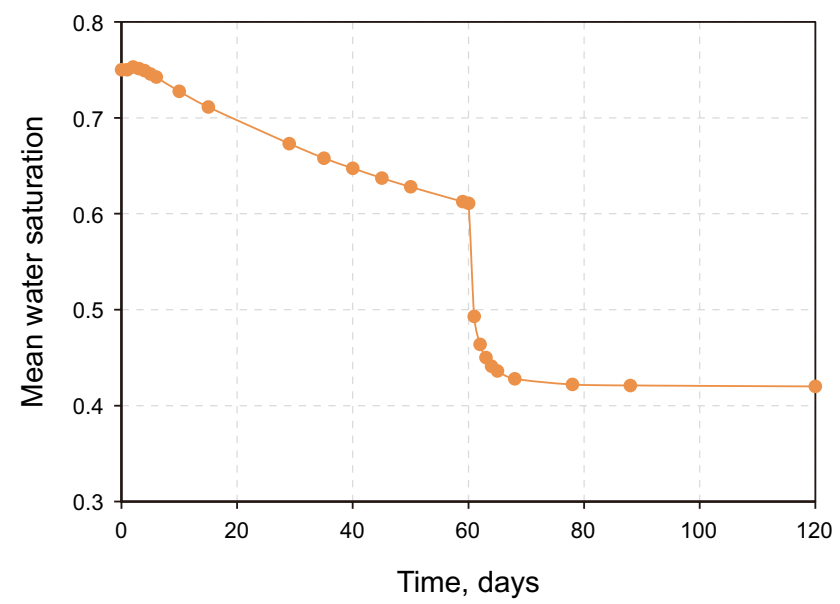

(a) Fracture

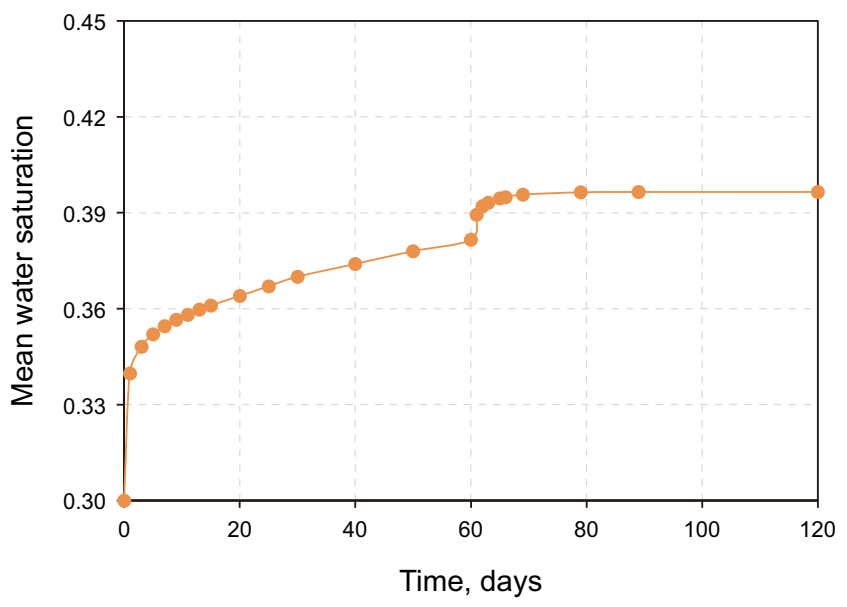

(b) Matrix surface

Fig. 13 Variations of the mean water saturation in fractures and the matrix surface

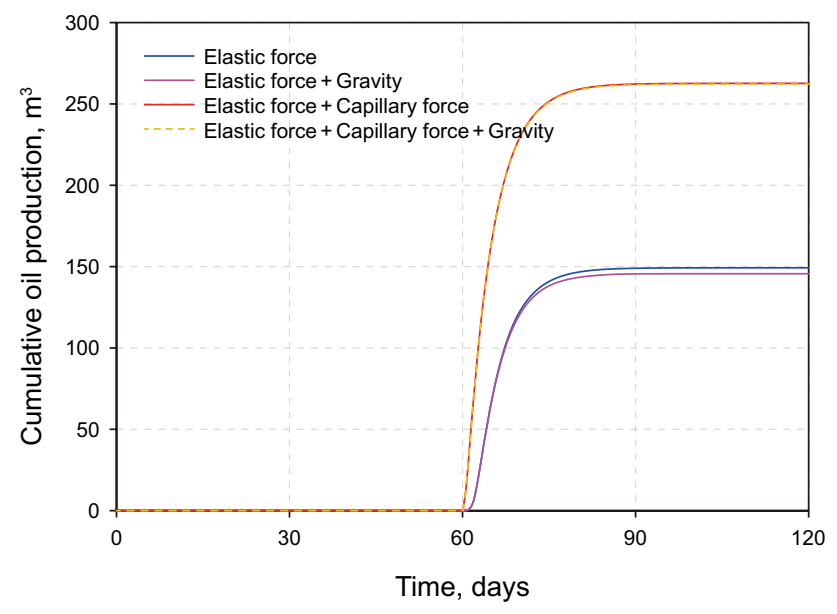

Fig. 14 Cumulative oil productions of considering different mechanisms

\subsubsection{Optimal soaking time}

According to the above simulations, the pressure propagation and imbibition occur during high-pressure soaking. They decide the oil production at the depressurizing stage. Figure 20 shows the oil production for different soaking times. We can see that the oil production increases to a plateau after producing for several days. Both the rising rate and the oil production increase as the soaking time increases. Despite longer soaking time works better, the oil production increases slowly when the soaking time gets longer. Therefore, there must exist an optimal value of soaking time for highly efficient development. We take 10 days as a step and compare the oil production. If the soaking time is increased by 10 days, while the

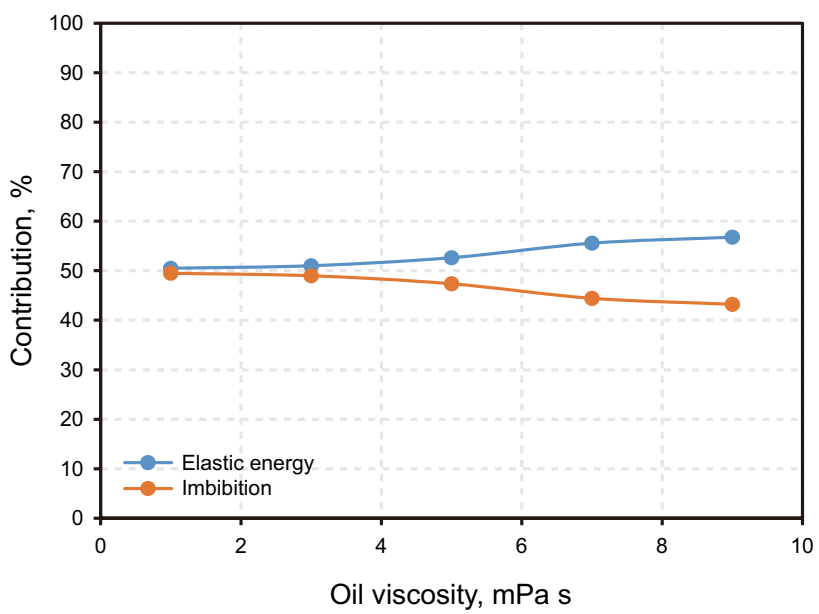

Fig. 15 The impacts of oil viscosity on the contribution of different mechanisms

yield is increased by less than $5 \%$, the best soaking time is obtained.

Figure 21 shows the impact of oil viscosity on the optimal soaking time. The relation between the optimal soaking time and oil viscosity is as follows:

$t_{\text {soak }}=3.5 \mu_{\mathrm{o}}+37.5$.

Figure 22 shows the impact of BHP on the optimal soaking time. The optimal soaking time linearly changes as the BHP increases, and the relation is as follows:

$t_{\mathrm{soak}}=2 p_{\mathrm{wf}}+30$. 


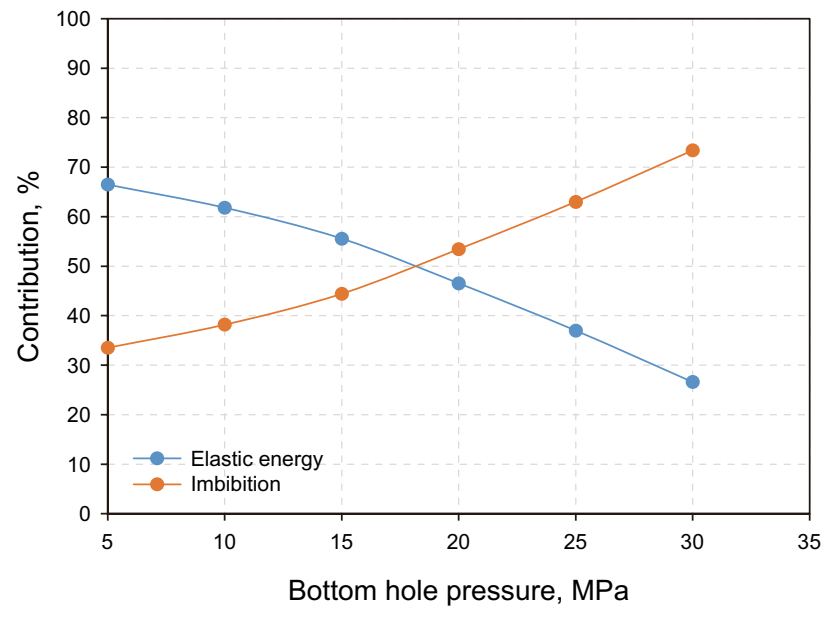

Fig. 16 The impacts of BHP on the contribution of different mechanisms

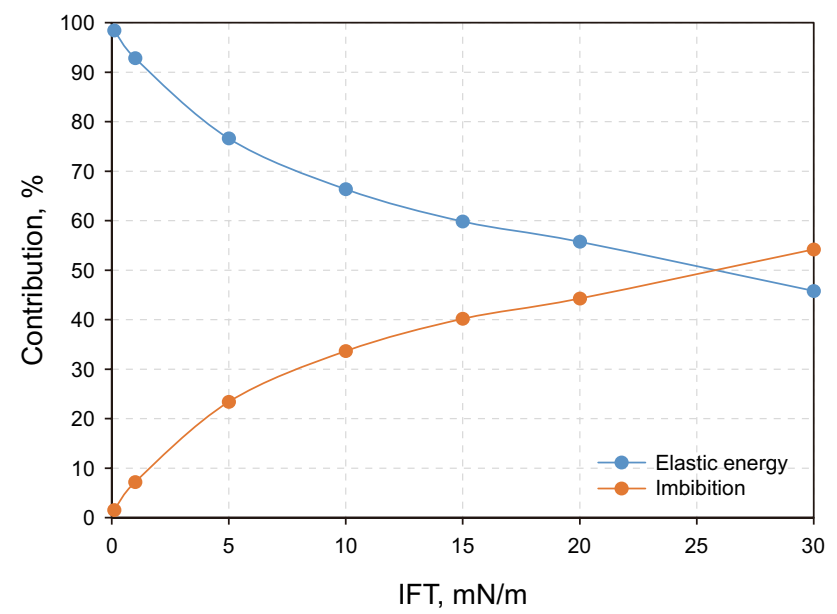

Fig. 17 The impacts of IFT on the contribution of different mechanisms

Figure 23 shows the impact of IFT on the optimal soaking time. When the IFT is lower, imbibition is very weak. It just takes little time to reach the balanced pressure, which is about 10 days. As the IFT increases, imbibition gradually strengthens, so it needs a longer time to conduct imbibition. A logistic function can be used to approximately describe their relationship:

$t_{\text {soak }}=\frac{65}{1+\exp \left(1.875-\sigma_{\mathrm{ow}} / 4\right)}$.

Figure 24 shows the impact of matrix permeability on the optimal soaking time. We can see that the optimal soaking time logarithmically declines as the permeability increases:

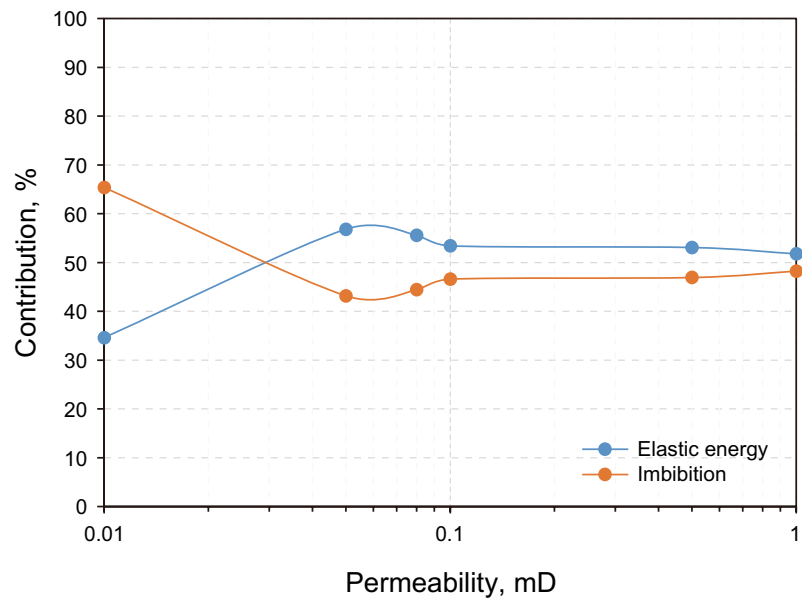

Fig. 18 The impacts of matrix permeability on the contribution of different mechanisms

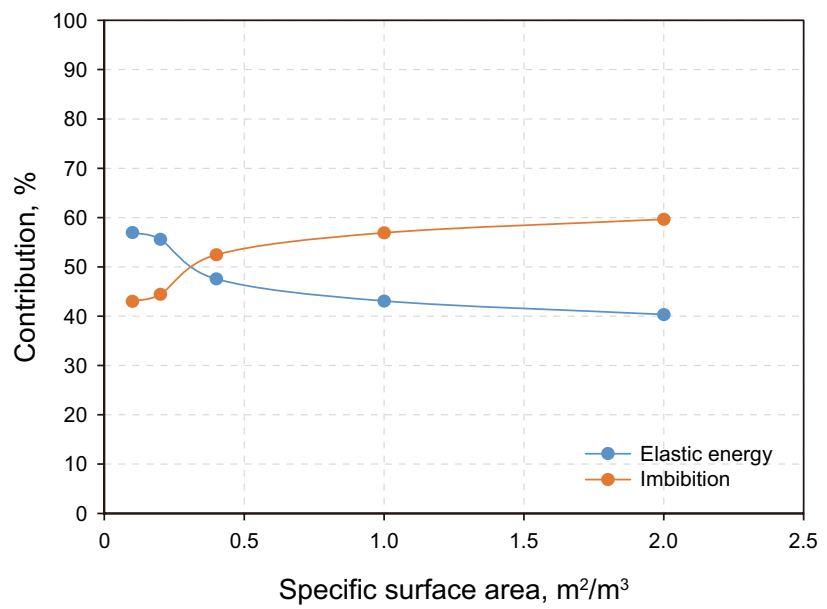

Fig. 19 The impacts of specific surface area on the contribution of different mechanisms

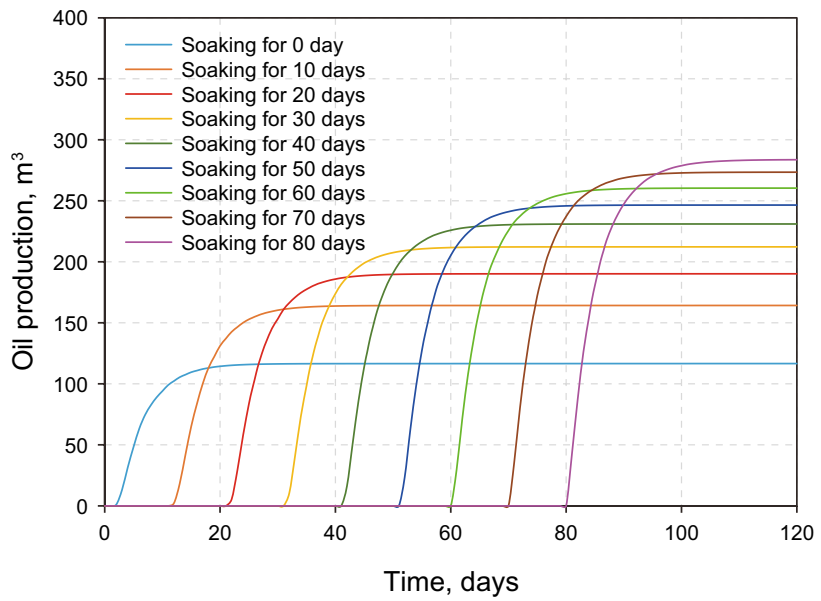

Fig. 20 Oil production for different soaking times 


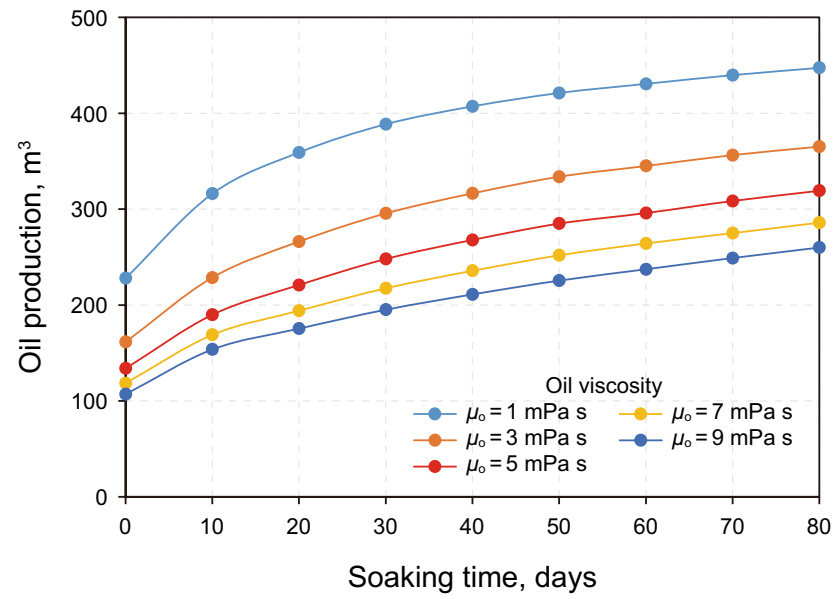

(a) Oil production vs. soaking time

Fig. 21 The impacts of oil viscosity on the optimal soaking time

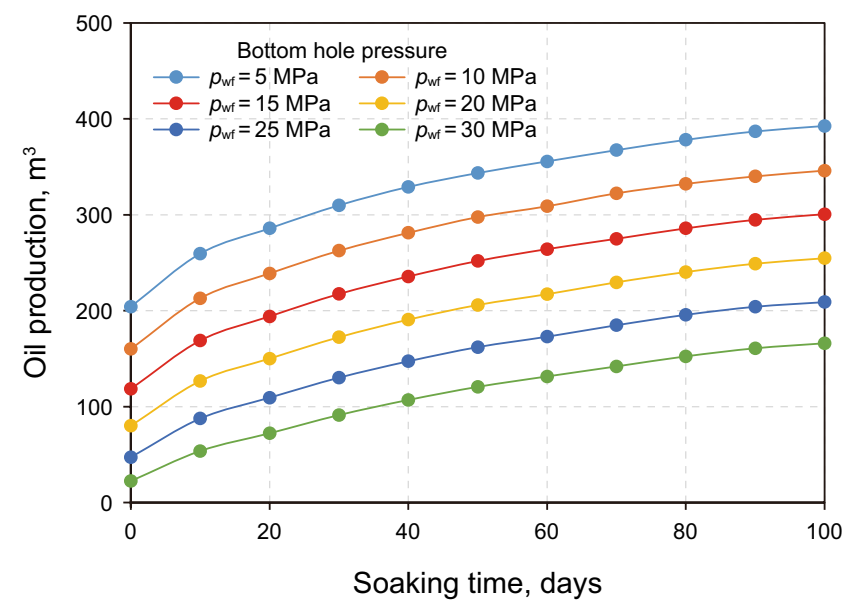

(a) Oil production vs. soaking time

Fig. 22 The impacts of bottom hole pressure on the optimal soaking time

$t_{\text {soak }}=40.4-6.82 \ln K$.

According to Eq. (11), when the permeability is lower, the capillary force is larger. Imbibition plays an important role on oil production, so it takes a longer soaking time. As shown in Fig. 25, the optimal soaking time also logarithmically declines as the specific surface area $\left(A_{\mathrm{s}}\right)$ increases:

$t_{\text {soak }}=20.4-24.9 \ln A_{\mathrm{s}}$.

Therefore, the tight formations with conventional fracturing need a longer soaking time than that of the ones with stimulated reservoir volume (SRV).

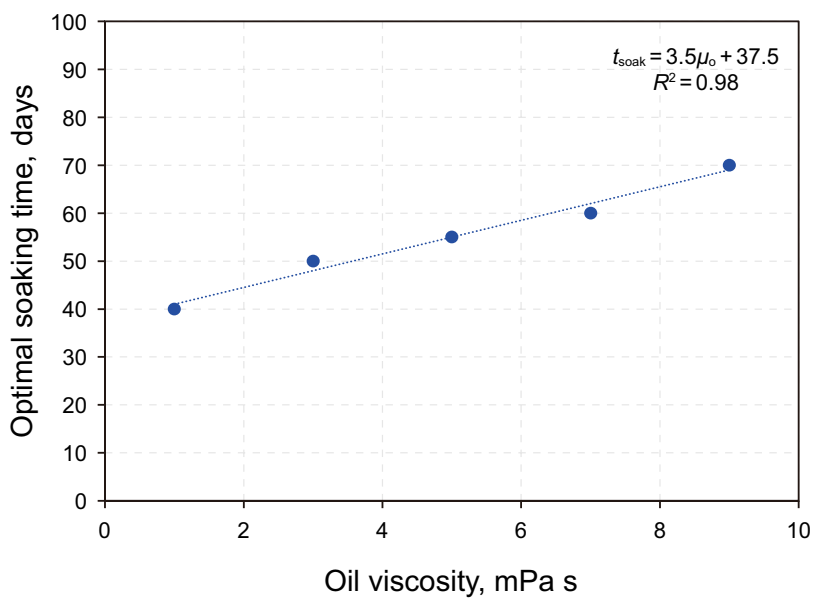

(b) Optimal soaking time vs. oil viscosity

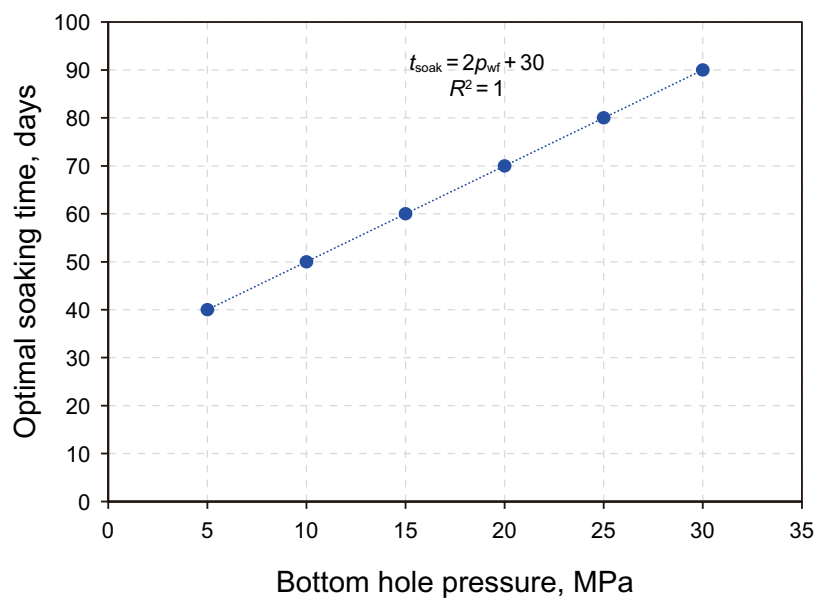

(b) Optimal soaking time vs. bottom hole pressure

According to the impacts of different factors on the soaking time, a general model was achieved to calculate the optimal soaking time for high-pressure soaking including the above factors:

$t_{\mathrm{o}}=3.18 \mu_{\mathrm{o}}-39.56 k+2.23 \sigma_{\mathrm{ow}}+2 p_{\mathrm{wf}}-34.9 A_{\mathrm{s}}-28$.

The agreement between the predicted results and experimental values is shown in Fig. 26.

\subsubsection{Performances of huff-n-puff}

After soaking by the fracturing fluid and depressurizing production, huff-n-puff would be carried out. Some simulations were performed to observe the huff-n-puff performances. 


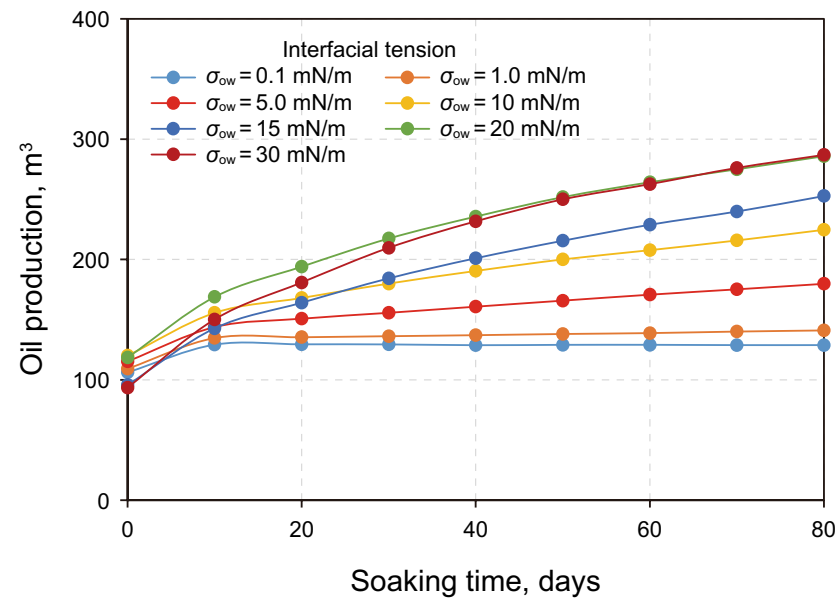

(a) Oil production vs. soaking time

Fig. 23 The impacts of interfacial tension on optimal soaking time

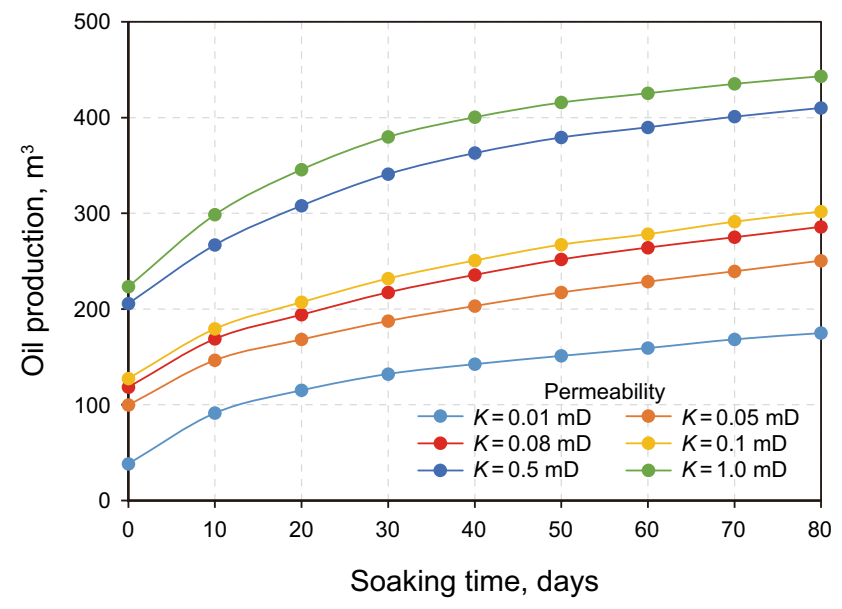

(a) Oil production vs. soaking time

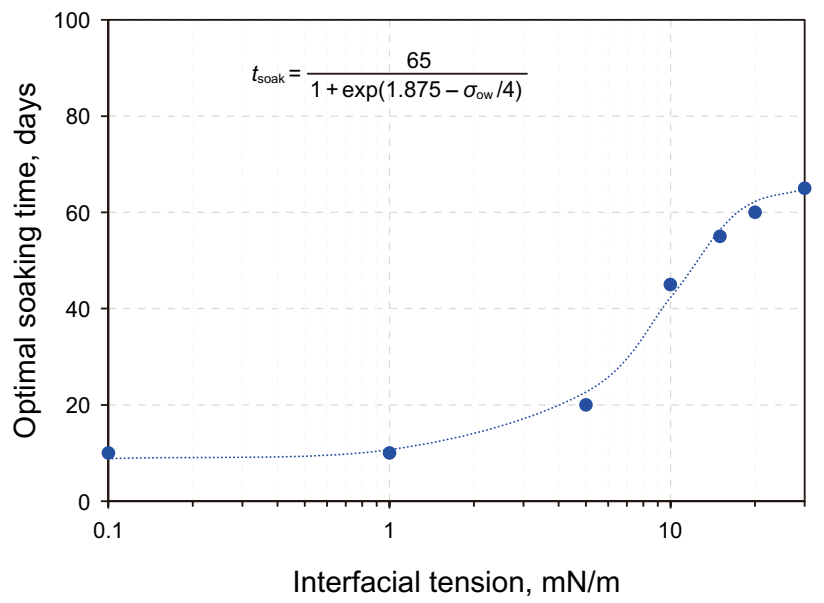

(b) Optimal soaking time vs. IFT

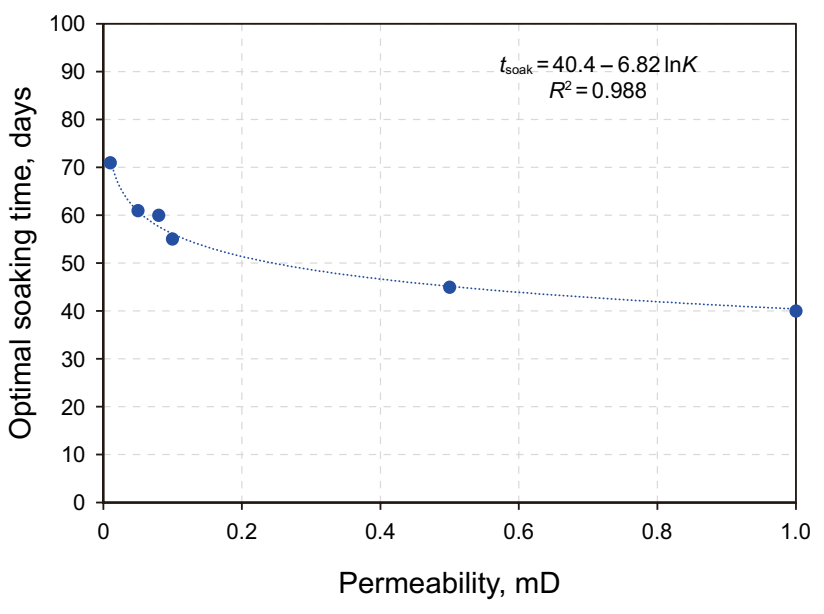

(b) Optimal soaking time vs. matrix permeability

Fig. 24 The impacts of matrix permeability on optimal soaking time

The first cycle is hydraulic fracturing - high pressure soaking-depressurizing production. After that, water is injected until the bottom hole pressure reaches $70 \mathrm{MPa}$, and the soaking is performed for a period of time. After soaking, the well produces at a constant bottom hole pressure of $15 \mathrm{MPa}$. The cyclic soaking and production times were optimized one cycle after another, and the flowchart is shown in Fig. 27.

Figure 28 shows the oil production performances of huffn-puff. We can see that both the oil production rate and the cycle oil production decrease from the first cycle to the last. The reason is that the fluid redistributes under the mechanisms of imbibition and elastic energy in each cycle. It can be explained by Fig. 1. After the first cycle, the distribution of fluid is shown in Fig. 1d. In the high-pressure transmission stage of the second cycle, the injected water enters from both ends of the capillary, and the length of water column increases. The difference between $P_{\mathrm{c} 1}$ and $P_{\mathrm{c} 2}$ gradually decreases to zero, so less fluid or oil could be driven out at forced imbibition stage. Correspondingly, less oil could be expelled from the wide end at the depressurizing stage. In addition, after the forward cycles, more water enters the ends of the capillary, so water will be produced firstly at the stage of the elastic energy release. For the above reasons, cycle oil production decreases from the first cycle to the last.

Figure 29 shows the oil productions and the optimal soaking times in different cycles. The optimal soaking times gradually decrease from 60 days in the first cycle to 0 day after eight cycles, but the optimal production times keep for 30 days in each cycle. The reason is that, on one hand, imbibition is proceeding in the early production process, so the 


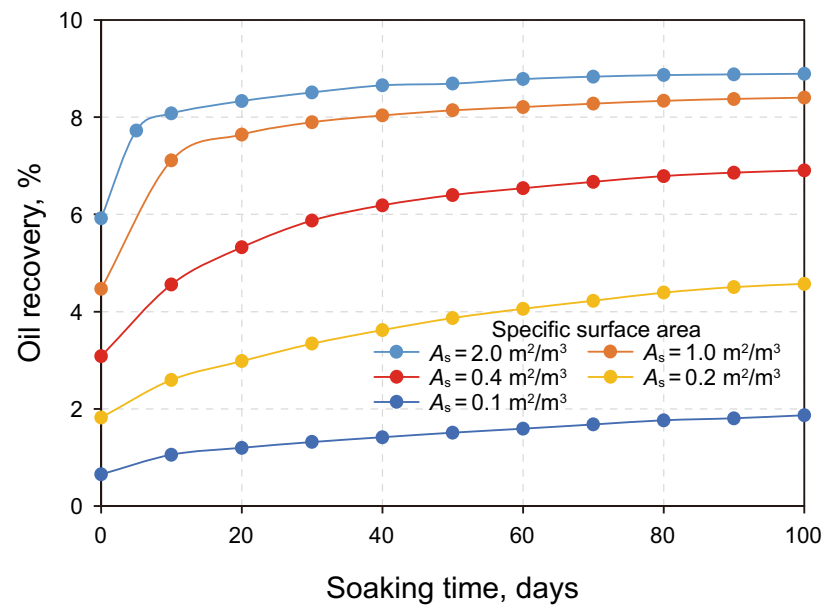

(a) Oil production vs. soaking time

Fig. 25 The impacts of specific surface area on optimal soaking time

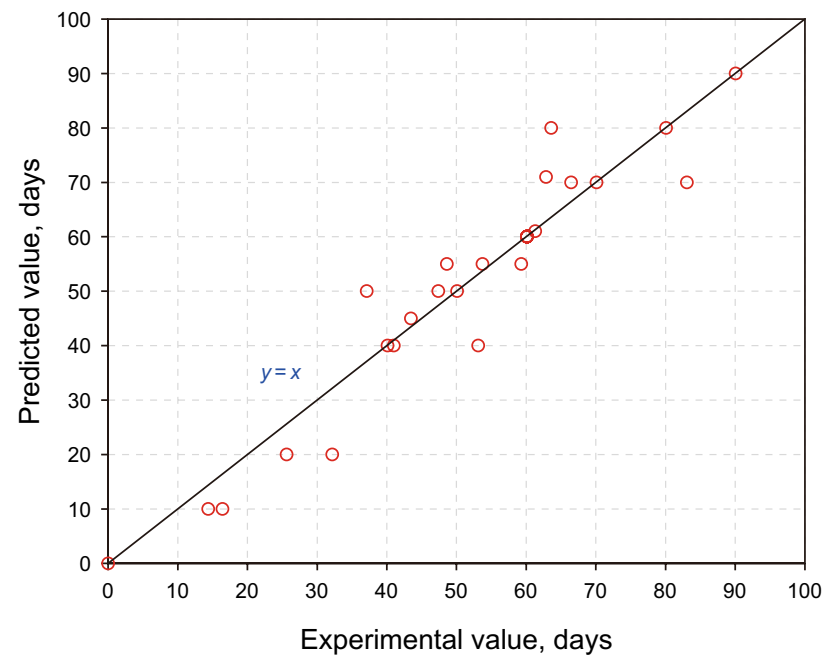

Fig. 26 The agreement between experimental and predicted values of optimal soaking times

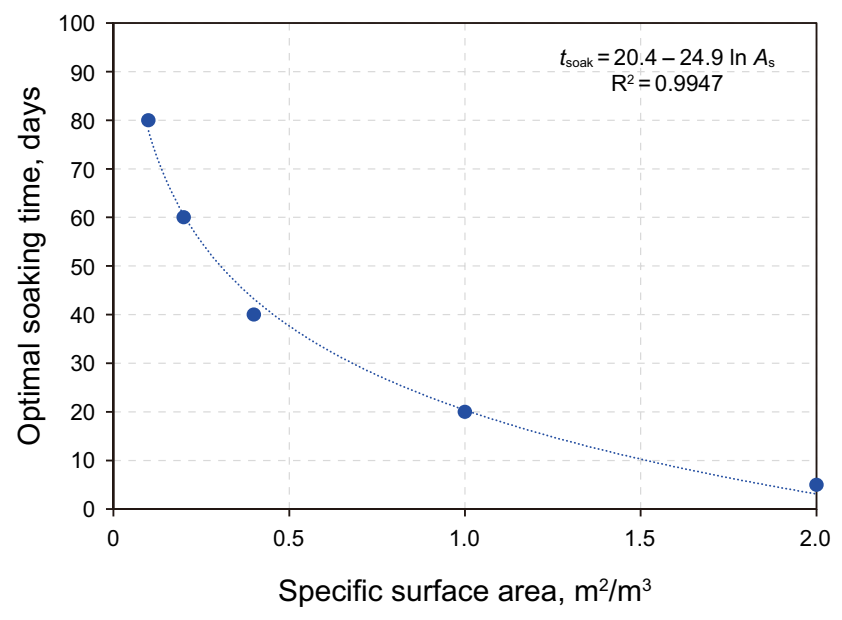

(b) Optimal soaking time vs. specific surface area

soaking time gradually decreases; on the other hand, since the difference between $P_{\mathrm{c} 1}$ and $P_{\mathrm{c} 2}$ decreases, the imbibition equilibrium is much easier to be reached. Therefore, a longer soaking time should be chosen at the first several cycles, and more oil can be recovered. Combining with Fig. 28, the economic benefit should be evaluated for the lowly periodic oil production after several cycles.

Figure 30 shows the water production/injection performances of huff-n-puff. All of the water-cut, cycle water production, and cycle water injection are the largest in the first cycle (hydraulic fracturing and backflow stage). Both the water-cut and cycle water production gradually increase from the second cycle, but the cycle water injection is very close. The reason is that the fractures are full of water after hydraulic fracturing and part of the oil is flooded far away the wellbore, so the water-cut is high at first. After the injected water flows back, an amount of oil in the fractures and less water are produced, so the water-cut decreases. From the

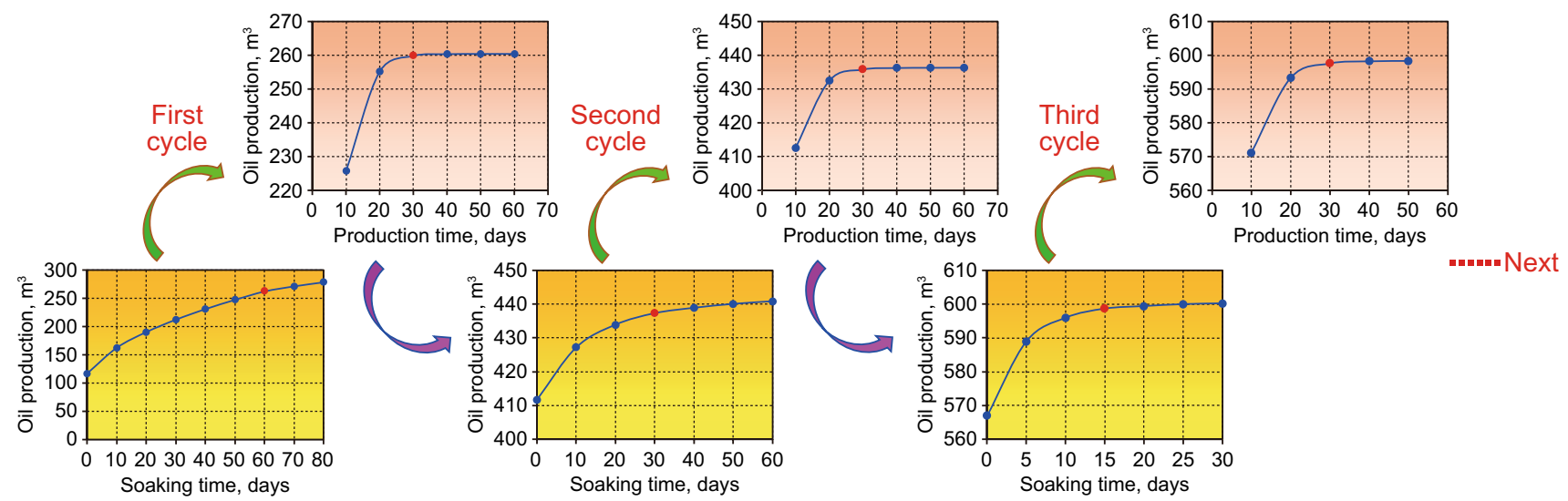

Fig. 27 The flowchart of optimizing the optimal soaking and production times for each cycle 


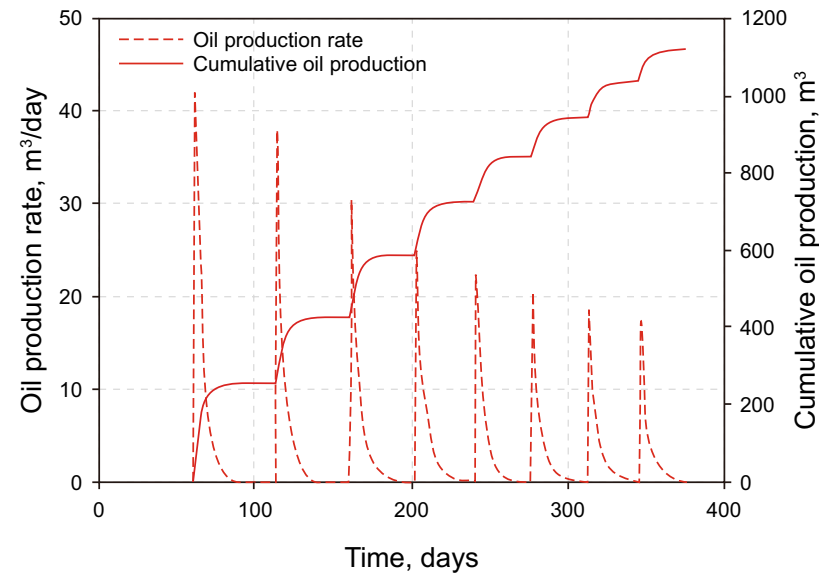

Fig. 28 Oil production performances of huff-n-puff

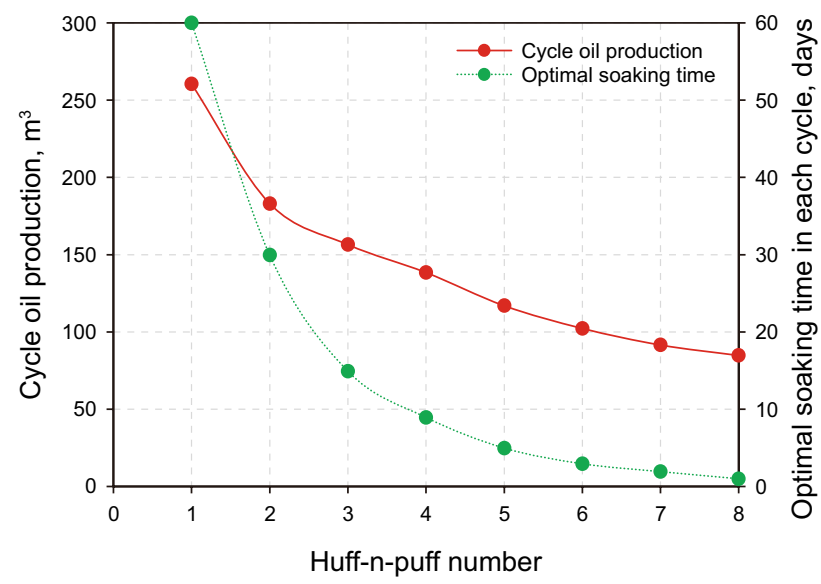

Fig. 29 Oil productions and optimal soaking times in different cycles

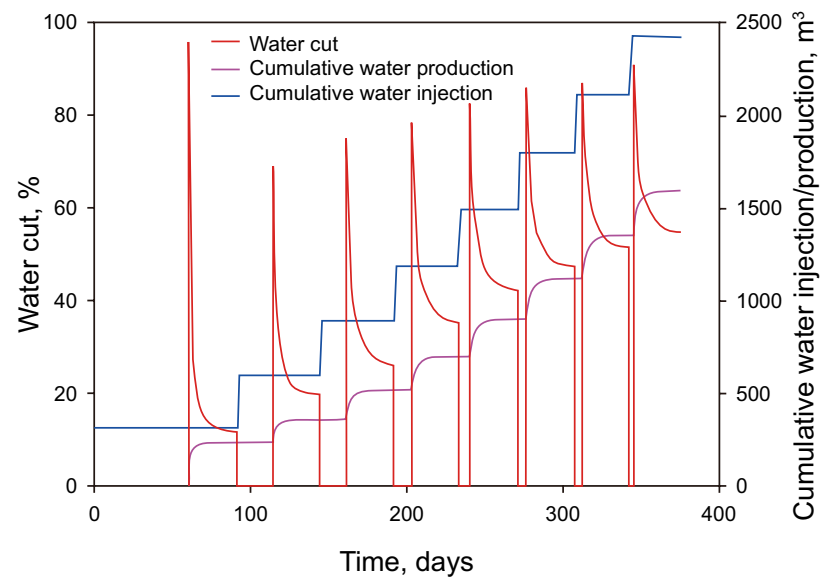

Fig. 30 Water production/injection performances of huff-n-puff

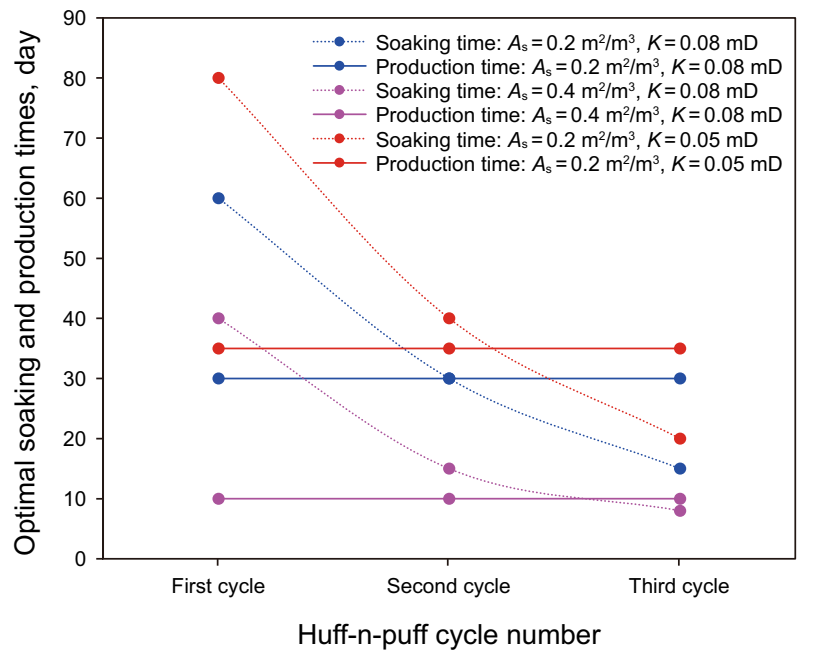

Fig. 31 The impacts of matrix permeability and specific area on the optimal soaking and production times

second cycle, the oil in fractures gradually decreases and cycle water injection is close, so the water-cut increases.

The optimal soaking and production times in different scenarios were also studied. Figure 31 shows the impacts of matrix permeability and specific area on the optimal soaking and production times. It is clear that the optimal soaking time gradually decreases and the optimal production time does not change in different scenarios. The optimal soaking and production times decrease as the specific area increases, but increase as the matrix permeability decreases. Therefore, we can choose a shorter soaking and production time for the reservoirs with high permeability or stimulated reservoir volume (SRV).

\subsection{Limitations of our study}

Although we have demonstrated a significant study of highpressuring soaking, the real process is more complicated. In our study, phase entrapment during leak-off and flow-back is neglected. The injected water may have a negative influence on tight formations due to permeability reduction, which is attributed to water sensitivity. Therefore, the optimal time will slightly decrease in such circumstance. In addition, soaking is also important for recovering the reservoir temperature near the wellbore after hydraulic fracturing, especially for the crude oil with high viscosity or wax content. 


\section{Conclusions}

A whole process of pressurizing, high-pressure soaking, and depressurizing was analyzed to understand the capacity and mechanisms of high-pressure soaking after hydraulic fracturing. A mechanistic model was established and verified. Finally, a simulation method was employed to address the concerns about the mechanisms and capacity of high-pressure soaking. The key findings are summarized as follows,

- High-pressure soaking has a significant impact on oil production through the mechanisms of imbibition and elasticity, both of which have considerable contributions. Imbibition works at the soaking stage, and elasticity works at the depressurizing stage.

- High-pressure soaking could make more water enter the matrix even in mixed-wet rocks. About $20 \%$ of the fracturing fluid flows back after adequate soaking in waterwet rocks. For water-wet or mixed-wet rocks, the flowback rate after soaking is less than that without soaking.

- The contribution of imbibition increases as the increase in BHP, IFT, and specific surface area. However, it slightly decreases as the oil viscosity increases, and first decreases and then slightly increases as the increase in matrix permeability.

- The optimal soaking time increases linearly as the oil viscosity and BHP increase. It logarithmically declines with the increase in matrix permeability and specific surface area. Moreover, it shows a rising trend as the IFT increases.

- During huff-n-puff, cyclic oil production decreases from the first cycle to the last one. The optimal soaking time of each cycle gradually decreases, but the optimal production time is unchanged. The optimal soaking and production times decrease as the specific area increases, but increase as the matrix permeability decreases.

- Both water production and injection in the first cycle are the largest. The cyclic water cut and water production gradually increase from the second cycle, but the cyclic water injections are very close.

\footnotetext{
Acknowledgements This work was supported by the National Natural Science Foundation of China (No. 52074316), Science Foundation of China University of Petroleum, Beijing (No. 2462018QNXZ01), Open Fund (No. SXCU-201905) of Shaanxi Cooperative Innovation Center of Unconventional Oil and Gas Exploration and Development (Xi' an Shiyou University), National Basic Research Program (No. 2015CB250906), and National S\&T Major Project (No. 2017ZX05009004).
}

Open Access This article is licensed under a Creative Commons Attribution 4.0 International License, which permits use, sharing, adaptation, distribution and reproduction in any medium or format, as long as you give appropriate credit to the original author(s) and the source, provide a link to the Creative Commons licence, and indicate if changes were made. The images or other third party material in this article are included in the article's Creative Commons licence, unless indicated otherwise in a credit line to the material. If material is not included in the article's Creative Commons licence and your intended use is not permitted by statutory regulation or exceeds the permitted use, you will need to obtain permission directly from the copyright holder. To view a copy of this licence, visit http://creativecommons.org/licenses/by/4.0/.

\section{References}

Abbasi M, Dehghanpour H, Hawkes RV. Flowback analysis for fracture characterization. In: SPE Canadian unconventional resources conference, Calgary, AB, Canada, 30 Oct-1 Nov 2012. https://doi. org/10.2118/162661-MS.

Alvarez JO, Tovar FD, Schechter DS. Improving oil recovery in unconventional liquid reservoirs by soaking-flowback production schedule with surfactant additives. In: SPE liquids-rich basins conference-North America, Midland, TX, USA, 13-14 Sep 2017. https ://doi.org/10.2118/187483-MS.

Babadagli T. Analysis of oil recovery by spontaneous imbibition of surfactant solution. In: SPE international improved oil recovery conference in Asia Pacific, Kuala Lumpur, Malaysia, 20-21 Oct 2003. https://doi.org/10.2118/84866-MS.

Begum M, Reza YM, Dehghanpour H, et al. Rock-fluid interactions in the Duvernay formation: measurement of wettability and imbibition oil recovery. In: SPE unconventional resources conference, Calgary, AB, Canada, 15-16 Feb 2017. https://doi. org/10.2118/185065-MS.

Burdine NT. Relative permeability calculations from pore size distribution data. JPT. 1953;5(3):71-8. https://doi.org/10.2118/225-G.

Cai JC, Perfect E, Cheng CL, et al. Generalized modeling of spontaneous imbibition based on Hagen-Poiseuille flow in tortuous capillaries with variably shaped apertures. Langmuir. 2014;30(18):5142-51. https://doi.org/10.1021/la5007204.

Cao P, Liu JS, Leong YK. A multiscale-multiphase simulation model for the evaluation of shale gas recovery coupled the effect of water flowback. Fuel. 2017;199:191-205. https://doi. org/10.1016/j.fuel.2017.02.078.

Corey AT. The interrelation between gas and oil relative permeabilities. Prod Mon. 1954;19:38-41.

Dutta R, Lee C, Odumabo S, et al. Quantification of fracturing fluid migration due to spontaneous imbibition in fractured tight formations. In: SPE Americas unconventional resources conference, Pittsburgh, PA, USA, 5-7 Jun 2012. https://doi. org/10.2118/154939-MS.

Finkbeiner T, Nawrocki P, Bratli RK, et al. The value of geomechanics in tight gas reservoir development. In: ISRM international symposium - 6th Asian rock mechanics symposium, New Delhi, India, 23-27 Oct 2010.

Goudarzi A, Delshad M, Mohanty KK, et al. Surfactant oil recovery in fractured carbonates: experiments and modeling of different matrix dimensions. J Pet Sci Eng. 2015;125:136-45. https://doi. org/10.1016/j.petrol.2014.11.008.

Habibi A, Binazadeh M, Dehghanpour H, et al. Advances in understanding wettability of tight oil formations. In: SPE Annual Technical Conference and Exhibition, Houston, Texas, USA, 28-30 September 2015. https://doi.org/10.2118/175157-MS.

Holditch SA, Tschirhart N. Optimal stimulation treatments in tight gas sands. In: SPE annual technical conference and exhibition, Dallas, TX, USA, 9-12 Oct 2005. https://doi.org/10.2118/96104 -MS. 
Huang H, Babadagli T, Chen X, et al. Performance comparison of novel chemical agents in improving oil recovery from tight sands through spontaneous imbibition. Pet Sci. 2020;17:409-18. https://doi.org/10.1007/s12182-019-00369-1.

Kathel P, Mohanty KK. Wettability alteration in a tight oil reservoir. Energy Fuels. 2013;27:6460-8. https://doi.org/10.1021/ef401 2752.

King GE. Thirty years of gas shale fracturing: what have we learned? In: SPE annual technical conference and exhibition, Florence, Italy, 19-22 Sep 2010. https://doi.org/10.2118/133456-MS.

Kong B, Wang SH, Chen SN. Simulation and optimization of $\mathrm{CO}_{2}$ huff-and-puff processes in tight oil reservoirs. In: SPE improved oil recovery conference, Tulsa, OK, USA, 11-13 Apr 2016. https://doi.org/10.2118/179668-MS.

Li XH. Application of cyclic water injection for tight oil production in the Tuha Oilfield. Spec Oil Gas Reserv. 2015;22(4):144-6. https://doi.org/10.3969/j.issn.1006-6535.2015.04.038.

Li ZX, Qu XF, Liu WT, et al. Development modes of Triassic Yanchang formation Chang 7 member tight oil in Ordos Basin, NW China. Pet Explor Dev. 2015;42(2):217-21. https://doi. org/10.1016/S1876-3804(15)30011-2.

Liang TB, Zhou FJ, Lu J, et al. Evaluation of wettability alteration and IFT reduction on mitigating water blocking for lowpermeability oil-wet rocks after hydraulic fracturing. Fuel. 2017;209:650-60. https://doi.org/10.1016/j.fuel.2017.08.029.

Lu J, Goudarzi A, Chen PL, et al. Enhanced oil recovery from hightemperature, high-salinity naturally fractured carbonate reservoirs by surfactant flood. J Pet Sci Eng. 2014;124:122-31. https ://doi.org/10.1016/j.petrol.2014.10.016.

Manrique EJ, Thomas CP, Ravikiran R, et al. EOR: current status and opportunities. In: SPE improved oil recovery symposium, Tulsa, OK, USA, 24-28 Apr 2010. https://doi.org/10.2118/13011 3-MS.

Mansour AG, Khalil R, Gamadi T. Compositional simulation evaluation of miscible gas injection performance in tight oil formation. In: SPE western regional meeting, Bakersfield, California, 23-27 Apr 2017. https://doi.org/10.2118/185680-MS.

Meng Z, Yang S, Cui Y, et al. Enhancement of the imbibition recovery by surfactants in tight oil reservoirs. Pet Sci. 2018;15:783-93. https://doi.org/10.1007/s12182-018-0253-y.

Omosebi AO, Igbokoyi AO. A two-dimensional reservoir simulator for expansion-drive reservoirs. In: Nigeria annual international conference and exhibition, Lagos, Nigeria, 6-8 Aug 2012. https ://doi.org/10.2118/162983-MS

Pourabdollah K. Process design of cyclic water flooding by real-time monitoring. ASME J Energy Resour Technol. 2018;140(11):112701. https://doi.org/10.1115/1.4040525.

Rangel-German ER, Kovscek AR. Experimental and analytical study of multidimensional imbibition in fractured porous media. J Pet
Sci Eng. 2002;36(1-2):45-60. https://doi.org/10.1016/S0920 $-4105(02) 00250-4$

Roychaudhuri B, Xu JY, Tsotsis TT, et al. Forced and spontaneous imbibition experiments for quantifying surfactant efficiency in tight shales. In: SPE western north American and rocky mountain joint meeting, Denver, Colorado, 17-18 Apr 2014. https://doi. org/10.2118/169500-MS.

Song CY, Yang DY. Performance evaluation of $\mathrm{CO}_{2}$ huff-n-puff processes in tight oil formations. In: SPE unconventional resources conference Canada, Calgary, AB, Canada, 5-7 Nov 2013. https:// doi.org/10.2118/167217-MS.

Thomas A, Kumar A, Rodrigues K, et al. Understanding water flood response in tight oil formations: A case study of the Lower Shaunavon. In: SPE/CSUR unconventional resources conferenceCanada, Calgary, AB, Canada, 30 Sep-2 Oct 2014. https://doi. org/10.2118/171671-MS.

Teklu TW, Zhou Z, Li XP, et al. Experimental investigation on permeability and porosity hysteresis of tight formations. In: SPE low perm symposium, Denver, CO, USA, 5-6 May 2016. https://doi. org/10.2118/180226-MS.

Tuero F, Crotti MM, Labayen I. Water imbibition EOR proposal for shale oil scenarios. In: SPE Latin America and Caribbean petroleum engineering conference, Buenos Aires, Argentina, 17-19 May 2017. https://doi.org/10.2118/185560-MS.

Valiveti DM, Meier HA, Liu F, et al. Numerical simulation of 3D hydraulic fractures in poro-elastic rocks. In: 13th ISRM international congress of rock mechanics, Montreal, Canada, 10-13 May 2015.

Wang DM, Seright RS, Zhang J. Wettability survey in Bakken shale using surfactant formulation imbibition. In: SPE improved oil recovery symposium, Tulsa, OK, USA, 14-18 April 2012. https ://doi.org/10.2118/153853-MS.

Wang J, Liu HQ, Zhang J, et al. Experimental investigation on water flooding and continued EOR techniques in buried-hill metamorphic fractured reservoirs. J Pet Sci Eng. 2018;171:529-41. https ://doi.org/10.1016/j.petrol.2018.07.051.

Williams-Kovacs JD, Clarkson CR, Zanganeh B. Case studies in quantitative flowback analysis. In: SPE/CSUR unconventional resources conference, Calgary, AB, Canada, 20-22 Oct 2015. https://doi.org/10.2118/175983-MS.

Yang L, Wang S, Cai JC, et al. Main controlling factors of fracturing fluid imbibition in shale fracture network. Capillarity. 2018;1(1):1-10. 